\title{
RELACIONES INTERTERRITORIALES \\ EN EL SURESTE DE LA PENÍNSULA IBÉRICA DURANTE LA BAJA EDAD MEDIA: CARTAS, MENSAJEROS Y CIUDADES EN LA FRONTERA DE GRANADA ${ }^{1}$
}

\author{
INTERTERRITORIAL RELATIONS IN THE SOUTH EAST OF THE IBERIAN PENINSULA \\ DURING THE LATER MIDDLE AGES: \\ LETTERS, MESSENGERS AND TOWNS ON THE FRONTIER OF GRANADA
}

\begin{abstract}
Resumen: Los contactos institucionales entre las coronas aragonesa, castellana y granadina en el Sureste de la Península Ibérica resultaron particulares a causa de la peculiar geografía política fruto del proceso de conquista cristiana desde mitad del siglo XIII. Mensajeros y delegados de las tres entidades políticas marcharon arriba y abajo de las fronteras asentando una doble estructura de comunicación: la propia de los poderes centrales que representaban, y la de los núcleos interesados en mantener un sistema estable de supervivencia. La organización social del espacio en este territorio encontró en las ciudades de Orihuela, Vera y Lorca las referencias básicas para su desarrollo y evolución.
\end{abstract}

Palabras clave: Mensajeros; Frontera de Granada; Cautivos; Reino de Murcia; Gobernación de Orihuela.

\section{JUAN FRANCISCO JIMÉNEZ ALCÁZAR Universidad de Murcia}

\begin{abstract}
The institutional contacts between the Aragonese, Castilian and Grenadine crowns in the southeast of the Iberian Peninsula were partly conditioned by its peculiar political geography, related to the process of Christian conquest from the second half of the 13th century. Messengers and delegates of the three political entities went up and down the frontiers and established a communication structure, involving both the central powers that they represented, and the urban nuclei interested in maintaining a stable system of relationships which could guarantee their survival. Towns like Orihuela, Vera and Lorca are basic references to study how the social organization of space in this territory evolved at the time.
\end{abstract}

Keywords: Messengers; Frontier of Granada; Captives; Kingdom of Murcia; Government of Orihuela.

\section{SUMARIO}

0. Introducción.- 1. El marco político: 1.1. Granada. 1.2. Castilla. 1.3. ...y Aragón.- 2. Relaciones interregionales y contactos municipales: 2.1. El contacto castellano-aragonés. 2.2.

${ }^{1}$ Este trabajo se inscribe en el seno del proyecto de investigación La configuración histórica del español hablado en el antiguo reino de Murcia (ss. XIII-XVII), HUM2007-64902, financiado por el Ministerio de Educacion y Ciencia, convocatoria I+D+1 de 2007. 
El contacto castellano-nazarí. 2.3. El contacto granadino-aragonés. 2.4. El contacto a tres bandas.- 3. Mensajeros y delegados. El factor humano: 3.1. Nuestro mensajero. 3.2. Oficios fronterizos al servicio del contacto diplomático. 3.3. Castellano, catalán, árabe y hebreo en una frontera multilingüe: misivas, traductores e intérpretes.- 4. Conclusiones. La legitimación del poder local como interlocutor válido entre reinos.

\section{INTRODUCCIÓN}

La existencia del sultanato de Granada en los albores meridionales de las tierras de Castilla después del siglo XIII conllevó múltiples actividades, acciones y procesos desarrollados al amparo de ese contacto. Pero esa geografía política se complicó sobremanera en el sector suroriental de la Península Ibérica, aquél donde los castellanos se asomaban al Mediterráneo desde que el infante don Alfonso, dirigiendo las operaciones militares en nombre de su padre Fernando III, incorporó la plaza de Cartagena al patrimonio real en 1245. Cuando décadas después la irrupción de las tropas aragonesas de Jaime II situó la frontera sur del reino de Valencia en la Vega Baja del río Segura, el planteamiento que pretendo exponer y analizar se definió por una compleja red de relaciones diplomáticas entre todas las piezas existentes y que concretaban en sí mismas el contexto territorial gestado.

Durante cerca de dos centurias, el sistema de comunicación entre los poderes centrales, territoriales y locales se constituyó en una particular estructura de relaciones directas e indirectas que terminaron por vertebrar toda una realidad histórica que se prolongó mucho más allá de los límites acordados del ocaso medieval. La intervención de actores e instituciones se marca como el objeto en sí mismo de esa estructura, pues a través de ella se comprueba el entramado que soportó la organización espacial no sólo comarcal sino suprarregional de la zona.

La relación entre entidades políticas se produce, de forma habitual, de dos maneras posibles: bien por un contacto institucional, bien por un intermediario físico. Lo que se suele olvidar comúnmente es que esas mismas instituciones son el reflejo de una organización humana, de ahí que siempre haya una persona detrás de cada uno de los resortes de su funcionamiento y desarrollo. La Monarquía, las Cortes, los concejos (centrados en la Baja Edad Media peninsular)... fueron siempre muestra de decisiones y comportamientos, muy por encima de cualquier indicio de rigidez normativa que pueda parecer regular la actividad o la praxis de su desarrollo institucional (llámese poder, llámese afirmación de su existencia). En este sentido, los vínculos entre la propia entidad política y la sociedad que la genera y regula son los que deciden su propia imagen definitoria. Los límites de su expresión, tanto si se trataba del ejercicio de autoridad como si lo era simplemente en el plano iconográfico, quedarán marcados por la evolución de las personas que asumían su representatividad. La voz de cada una de esas instituciones se podía escuchar directamente a través del individuo (o individuos) que encarnaba el reconocimiento de su ejercicio (de manera legítima o no, y según la interlocución esa señal era percibida o no), o por algún canal que posibilita- 
se esa comunicación: aludo al mensajero como protagonista del medio, bien por medio de la palabra hablada o escrita.

La conformación de las grandes entidades regnícolas en Europa Occidental en los postreros años plenomedievales, hizo posible que en los momentos de la conquista del Sur y Levante de la Península Ibérica, Castilla, Aragón y Portugal significasen la imagen de una creciente y desarrollada Cristiandad frente al residuo islámico del sultanato de Granada. Los contactos inevitables entre estas grandes células políticas van a ser el objetivo de este estudio. La meta es mostrar, por un lado, el papel del intermediario a la hora de la expresión última en el trato directo entre instituciones situadas en la franja fronteriza castellano-aragonesa-nazarí, asumiendo aquél y éstas una legitimidad en el mismo momento en que la lejanía del poder central no podía ejercer una potestad efectiva; y por otro, la propia dinámica que vertebró la estructuración territorial compuesta por demarcaciones pertenecientes a distintos ámbitos políticos, pero que respondían a una misma inercia funcional. Fue esa distancia a los núcleos del poder monárquico, entendidos éstos como los que encarnaban la idiosincrasia de la existencia del reino (hablamos de Burgos, Valladolid, Valencia, la propia ciudad de Granada...), la que condicionó los diversos comportamientos de los distintos poderes satélites, enclavados en los extremos de la autoridad de ese poder central. El carácter de la autoritas llegaba aquí a su máxima expresión. Centraré el marco geográfico-político en el Sureste peninsular, donde la relativa estrecha franja territorial que delimitó el dominio aragonés, castellano y granadino, se muestra como el entorno ideal para realizar la propuesta, pues en sí misma configuró umbrales que esbozaron sus respectivos reinos.

\section{EL MARCO POLÍTICO}

Este primer estadio es imprescindible, pues la geografía política existente después del arbitrio de Torrellas, que profundizaba aún más los acuerdos de 1244 en Almizra, señalaba unos territorios pertenecientes a entidades regnícolas distintas en un muy corto espacio de terreno. Destacado el reino de Murcia como una auténtica cuña castellana hacia el Mediterráneo, flanqueada por tierras meridionales del rey de Aragón y por las orientales del sultán nazarí, en una franja de unos escasos cien kilómetros coincidieron demarcaciones pertenecientes a tres soberanías diferentes. Lo realmente peculiar de esta situación fue la lejanía a los centros de poder respectivos y que terminará por particularizar la circunstancia.

Efectivamente, la llegada de los castellanos en los inicios de la década de 1240 a la Sierra de Segura y a las últimas llanuras manchegas del Este (Chinchilla, Albacete y Hellín cayeron en manos de Fernando III entre 1240 y 1242) se garantizó con la firma del pacto de Alcaraz entre el monarca 
cristiano y el régulo musulmán de $\mathrm{Murcia}^{2}$. La etapa de Protectorado (126466), la posterior sublevación mudéjar y la eclosión repobladora posterior a través de la obra organizadora de Alfonso X, terminó por definir una demarcación integrada en el sistema plurirregional de Castilla señalada fundamentalmente por la existencia de un Adelantado Mayor del Reino de Murcia $^{3}$ y por la implantación de grupos humanos concentrados en las principales ciudades y villas. Murcia, como cabeça del regno, Lorca como clave fronteriza frente a Granada, Cartagena como sede episcopal restaurada y expresión mediterránea castellana, Mula, las encomiendas de Caravaca y Cieza, Yecla, Villena, Albacete, Moratalla, Hellín, etc. estaban acompañadas en un primer momento por el otro gran puerto del Sureste, Alicante, la importante madina de Orihuela, Jumilla, los núcleos del Vinalopó... Se había constituido un territorio uniforme en sus límites meridionales y occidentales con Granada y al Norte con el reino de Valencia. Pero esa extensa salida al mar Mediterráneo de Castilla iba a verse restringida después de los acuerdos de Torrellas-Elche de principios del siglo $\mathrm{XIV}^{4}$. En adelante, la geografía política murciana se estrechó, acercando aún más la distancia entre la soberanía del rey aragonés y la del sultán nazarí, o lo que era lo mismo, entre las posiciones de vanguardia de uno y otro: Orihuela y Vera, respectivamente. Ese reino de Murcia mermado, hecho que se traerá a colación en el posterior enfrentamiento entre los dos Pedros décadas después ${ }^{5}$, representará en adelante el patrimonio del monarca de Castilla hacia sus intereses mediterráneos. En realidad, será más una importancia política que comercial, sin desdeñar esta última. Por un lado, la configuración de la frontera oriental del reino de Granada quedó marcada desde los acuerdos de Alcaraz en 1243, y fijada con la conquista castellana de las plazas de Mula, Lorca y Cartagena en los dos años siguientes. En adelante, granadinos y castellanos compartirían frontera terrestre en exclusiva, resultando para los cristianos un reducto

\footnotetext{
${ }^{2} \mathrm{~A}$ pesar de los años transcurridos, siguen siendo referencia los trabajos del profesor Juan TORRES FONTES sobre las fronteras del Sureste peninsular durante la Edad Media: La delimitación del Sudeste peninsular: tratados de partición de la reconquista. "Anales de la Universidad de Murcia", VIII (1950), pp. 669-696, y La delimitación del Sudeste peninsular, "Anales de la Universidad de Murcia”, IX (1951), pp 439-455, sistematizando todo el proceso en su monografía: La reconquista de Murcia en 1266 por Jaime I de Aragón, Murcia, 1987. También cabe reseñar el estudio de Miguel RODRÍGUEZ LLOPIS sobre el desarrollo de toda la ocupación cristiana en la totalidad de la demarcación: La expansión territorial castellana sobre la Cuenca del Segura (1235-1325), "Miscelánea Medieval Murciana" (en adelante MMM), XII (1985), pp. $105-138$.

${ }^{3} \mathrm{~J}$. TORRES FONTES, Los adelantados mayores del reino de Murcia en el siglo XIII, en Documentos de Fernando IV, CODOM V, Murcia, 1980, pp. XV-XXII. Asimismo, hay que reseñar la reciente monografía sobre el tema de Braulio VÁZQUEZ CAMPOS: Adelantados y lucha por el poder en el reino de Murcia, Alcalá la Real, 2009.

${ }^{4} \mathrm{M}^{\mathrm{a}}$ Teresa FERRER I MALLOL, Entre la paz y la guerra. La Corona catalano-aragonesa y Castilla en la Baja Edad Media, Barcelona, 2005. En el séptimo centenario de aquellos acontecimientos, se celebró un magno encuentro científico que fue publicado en el número 11 de la revista "Anales de la Universidad de Alicante. Historia Medieval", año 1997, al que remitimos para referir los numerosos y distintos estudios que allí se presentaron.

5 "El regno de Murçia que yo gane del rey de Aragon", palabras recogidas de una misiva de Pedro I de Castilla a los concejos de Elche, Alicante, Guardamar y resto del territorio alicantino (junio de 1364), durante la Guerra de los Dos Pedros. Angel Luis MOLINA MOLINA, Repercusiones de la guerra castellano-aragonesa en la economía murciana (1364-1365), "MMM", 3 (1977), p. 134 .
} 
particular casi privado; Granada fue en adelante su coto, cuyos frutos y rendimientos se verán surgidos de las posibilidades de expansión territorial, de zona de refugio, de prestigio para las acciones individuales (leamos Fernando de Antequera o Álvaro de Luna) y de recurso comercial. Los esfuerzos de Jaime II por asomarse al mar de Alborán y tener un mejor acceso al Magreb sólo dieron resultado en los acuerdos de Torrellas, pues terminó por controlar el puerto de Alicante. El mapa político existente en los años de dominio aragonés (1296 hasta 1304, sobre todo en los cuatro últimos años) variaba sustancialmente de lo que había sido la configuración alfonsí, y fundamentalmente, de lo que terminó siendo la cartografía posterior. El control por el Rey Justo de la plaza de Lorca daba opción a las huestes aragonesas para la conquista de mayores tierras en la franja mediterránea. El arbitrio con Castilla y la devolución de buena parte de los territorios murcianos conquistados, incluida la capital y el puerto de Cartagena (rectificación de Elche en 1305), no alteró el anhelo del monarca aragonés, de manera que en los acuerdos de Alcalá de Henares a finales de esa misma década se contempló el reparto conquistador del reino nazarí, donde a Aragón le correspondía un sexto. La cruzada de 1309, con el deseo de conquistar el puerto de Almería, se hizo bajo estos auspicios. Su estrepitoso fracaso no hizo otra cosa sino ahondar en la fijación de los límites fronterizos de 1304.

\subsection{Granada...}

Es cuestión conocida la del proceso de formación del reino nazarí de Granada tras la sublevación de Muhammad en Arjona y la muerte de Ibn Hud en Almería en $1238^{6}$. El control de la madina de Vera, en las cercanías de la costa del Levante almeriense e inmediatamente al sur de la desembocadura del Almanzora, llevó a articular en la zona oriental de los restantes dominios islámicos en la Península un sistema de jerarquización defensiva que permitiese soportar la hegemonía castellana con ciertas garantías. La presencia de meriníes y zenetes en el sector, parejo al hecho de la debilidad poblacional castellana en el conjunto del reino de Murcia a causa del fracaso de los proyectos repobladores alfonsíes (por cuanto no se cubrieron las expectativas), hizo que la estabilización fronteriza en las demarcaciones más próximas a la marina (y por lo tanto más estratégicas) fuese una realidad en adelante. Vera se convirtió en el referente espacial del rey de Granada, del Islam peninsular y pieza clave del sistema fronterizo del sector desde esas primeras décadas de presencia castellana en la demarcación.

Terminó asumiendo la capitalidad de la $t a ' a$. Sus cadíes, dependientes directamente del mayor de Granada, representarán la soberanía del sultán en la zona, en su expresión más directa, junto a la militar de los alcaides de las

\footnotetext{
${ }^{6}$ Miguel Ángel LAdERo QuESADA, Granada. Historia de un país islámico, Madrid, 1989. También está siendo un referente la obra conjunta sobre la Historia del Reino de Granada, vol. I, volumen coordinado por Rafael G. PEINADO SANTAELLA, Granada, 2000, donde se concentran diversos estudios que enfocan el desarrollo del Sultanato desde diversos escalones temáticos y cronológicos.
} 
distintas plazas de la demarcación (Huércal, Overa, Zurgena, Mojácar, etc.) ${ }^{7}$. Su constitución como ciudad-base de la frontera oriental nazarí frente al reino de Murcia va a estar reflejada en diversos momentos, comenzando por la apuesta decidida de los sultanes nazaríes porque no fuese una plaza posible de ser amenazada, como sí lo fueron los Vélez (que cayeron coyunturalmente en manos cristianas en la ofensiva de 1436), Overa, Albox o sobre todo Huéscar, que fue reconquistada por los granadinos en dos ocasiones (una en cada siglo) hasta su pérdida definitiva por los cristianos en la guerra de conquista final de los Reyes Católicos. El sistema defensivo al Oriente de la capital granadina se componía de cuatro grandes hitos: Baza, que protegía el Noroeste y la vía de penetración hacia la Vega (Guadix quedaría desguarnecida), las Alpujarras como presa de contención natural, Almería como gran puerto, y Vera como su antesala. De hecho, cuando Fernando el Católico tomó por capitulación todo el sector oriental granadino en junio-julio de 1488, lo hizo gracias a que la ciudad veratense pactó su rendición. El resto de plazas (cincuenta en palabras de las crónicas ${ }^{8}$ ) se entregó a la vez sabedoras de que se habían quedado sin referente político, territorial, económico ni militar. Además de los textos coetáneos, contamos con varios testimonios, uno de los cuales fue realizado años después en un pleito (que expondré a continuación), donde el morisco García de Quesada recordaba cómo había visto al rey don Fernando (vestido de rojo y oro) y en la Fuente Grande donde estaba acampado, y que acudieron el Macarche por Bédar, Almaf Canif por Serena, Avonjauher por Cabrera y Uçaf por Teresa, además de otros individuos en representación de otros tantos lugares que no recordaba, a entregarse al rey ${ }^{9}$. Vera jugaba el papel estratégico y el resto de enclaves el táctico. Su caída llevó la frontera hasta la línea Baza-Almería durante los cercos de 1490 mezclados con la acción política de Çidi Yahya Al-Nayar.

Con posterioridad, la apertura de un extenso e interminable pleito por el campo de Huércal entre las ciudades de Vera y Lorca (un litigio más de los interpuestos que buscaban la definición territorial del espacio en el marco de la estructura organizativa municipal castellana), nos ofrece a los investigadores testimonios excepcionales acerca de la jerarquización existente. Un testigo llega a exponer que Vera hera la madre de ellos [los enclaves de Huércal y Overa $]^{10}$, señal inequívoca de lo que representaba para toda la demarcación en tanto que suponía la base que sostenía el sistema defensivo: E demas de esto, hablando este testigo algunas vezes con vezinos de la dicha Huercal, les dezia

\footnotetext{
${ }^{7}$ María ARCAS CAMPOY Cadíes y alcaides de la frontera oriental nazari (s. XV), "AlQantara", XX-2 (1999), pp. 48̀7-501.

${ }^{8}$ Valera y Bernáldez dan cuenta de ello, aunque recojo en este momento el texto de la Historia de los hechos del marqués de Cádiz: "Despues de avida tanta vitoria, y ganadas la cibdad de Vera y muchas otras villas y lugares y fortalezas, en numero por todas çinquenta y tantas..." (estudio preliminar de Juan Luis CARRIAZO, Granada, 2003, p. 302). La referencia de la caída de Vera será permanente como hito cronológico en la Guerra de Granada, marcando el año 1488 con esa conquista, de la misma manera que lo fue 1482 por Alhama, 1487 por Málaga o 1490 por Baza y Almería.

${ }^{9}$ Archivo de la Real Chancillería de Granada (en adelante ARCG). 454-1.

${ }^{10}$ Ibídem. Testigo Martín Adulahacis.
} 
que si los de Lorca ge viniesen sobre ellos, qué harían o qué remedio pornian. E le dez[ian] e dixeron que tenían hecho conçierto que haziendo un haumada en la torre de Huercal, que luego avia de venir gente de Vera a guaresçe$l l o s^{11}$. Pero la designación de la competencia militar, por la propia idiosincrasia del poder islámico, recaía en el sultán, que era quien investía a los alcaides de todas las fortificaciones de forma directa ${ }^{12}$. Este hecho no debe hacernos caer en el error de pensar que se amortiguaba la potestad militar del núcleo veratense, pues en último término, la primera interesada en el sostenimiento de las posiciones más avanzadas era la propia ciudad de Vera. La respuesta en las zonas de frontera venía a ser más o menos similar, donde la asunción de papeles de autodefensa se correspondía más con la necesidad de respuesta rápida que del abandono del poder central. Este aserto es fundamental para lograr entender lo que pretendo como objetivo básico, pues es lo que terminó por asentar el sistema de encarnación de autoridad por parte de instituciones locales, legitimando a su vez a los distintos poderes centrales, en este caso el del sultán nazarí. No fue el mandato directo del rey granadino quien ordenó edificar la torre defensiva en la Ballabona, sino el propio alcaide de Vera, Zeyén, para compensar el sistema fronterizo en las inmediaciones de la desembocadura del Almanzora, junto a Overa ${ }^{13}$. Sí era un mandato indirecto, pues lo hacía a través de la delegación ordenada al alcaide veratense. Y ésa es la clave para la legitimación en las distintas actuaciones.

Llegado este punto, conviene aludir a un comentario que no tendría la mayor importancia en boca de un testigo morisco durante un pleito del XVI, si no fuese porque es altamente indicativo de la referencia espacial que se trasfiere de ese testimonio. Luis de Carmona el Xoraguad, vecino de Líjar, aludía al "reyno de Almeria" ${ }^{14}$ cuando fue preguntado por una cuestión puntual sobre el dominio de Vera sobre su entorno territorial (responderá por lengua de un intérprete latente $)^{15}$. Granada quedaba lejos, y la última mención alusiva a un lugar señalado fue la ciudad de Almería. Volveré sobre este

${ }^{11}$ Ibídem. En ese mismo sentido, y ahondando más en la cuestión, incluyo un fragmento igualmente significativo: "E porque algunas vezes de que en tiempo de la guerra faltava alguna gente para la guarda de los dichos lugares de Overa e Huercal, la çibdad de Vera e justiçia de ella sacava mançebos, hijos de vezinos de la dicha çibdad, y los hazian ir, aunque no querían, a velar e guardar los dichos lugares porque estavan en frontera, espeçialmente a Huercal que estava en mas peligro". Testigo vigésimo octavo a la vigésimo sexta pregunta.

${ }^{12} \mathrm{Al}$ igual que los tenían algụnos de sus homólogos en la vanguardia castellana, los responsables de las fortalezas fronterizas nazaríes disfrutạan de determinados privilegios con el objeto de sostener las posiciones; y eso parece traslucirse del siguiente testimonió: que los alcaides y jurisdicción pertenecían a los reyes de Granada "espeçialmente que todos los lugares de la frontera como lo hera Huercal, que entre ellos ẹl rey moro ponía sus alcaides e sus guardas e defensas, e quel dicho alcaide gozava de los quintos e cavalgadas". Fernando Abduladín, morisco, vecino de Vélez Blanco. ARCG. 454-1.

${ }^{13}$ ARCG. Ibídem.

${ }^{14}$ Ibídem.

${ }^{15}$ Acerca del papel de los intérpretes activos en el periodo morisco, véanse los estudios de $\mathrm{M}^{\mathrm{a}}$ Mercedes ABAD MERINO, Intérpretes latentes y patentes en el periodo morisco (1501-1568), "MMM", XXIX-XXX (2005-2006), pp. 9-23, y El intérprete morisco. Aproximación a la Historia de la Traducción cotidiana en España en el ocaso de la Edad Media, "Hermeneus", 10 (2006), pp. 23-53. 
asunto con un ejemplo si cabe igualmente significativo, en este caso con Lorca y Murcia.

Queda claro pues que la ciudad de Vera se constituyó como un referente espacial indiscutible, tanto para el sultán de Granada como para los habitantes cristianos del reino de Murcia y del distrito meridional valenciano, leamos Orihuela.

\section{2. ...Castilla...}

El caso castellano es si cabe más complejo. Hay que tener presente que el sistema plurirregional existente en Castilla y León, desde el mismo momento en que se configura definitivamente la Corona como tal tras Fernando III (y a pesar de las tentaciones alfonsíes para la desintegración de los reinos meridionales en pleno debate sucesorio), conllevó que el reino de Murcia que se incorporó a esa estructura lo hiciera de una manera particularmente sinuosa. Lo que terminó en manos castellanas fue un residuo fruto de la desmembración política del reino hudí, el mismo proceso que generó el sultanato nazarí al que acabo de aludir. Si bien el pacto de Alcaraz condicionó que ese reino de Murcia, con capitalidad en la ciudad que le daba el nombre, fuese a parar a manos de control del monarca de Castilla, fue el tratado de Almizra el que terminó por concretar los planes de reparto previos entre los reyes cristianos de la propia Castilla y Aragón, desde Tudilén en 1151 (donde de manera muy interesante Alfonso VII el Emperador se reservaba el dominio de Lorca y Vera fuese cual fuese el destino del resto del territorio) hasta Cazola (1179).

La configuración de un reino lejano a los núcleos de poder castellano, allí por donde habitualmente se concentraba la actividad de los reyes, o de las regencias, de las Cortes, la zona más densamente poblada, y desde donde habían partido las huestes de conquista, fue posible gracias a una delimitación clara por parte de factores exógenos, y que han condicionado el resultado de un territorio que queda concretado más por lo que no es que por lo que termina siendo, el murciano. Sus referentes claros van a ser los núcleos principales que lo componían, proceso iniciado por el sistema de definición territorial castellano a través del esbozo de grandes concejos con amplios alfoces, en este caso fronterizos. Murcia no sólo prestará su nombre al conjunto del territorio identificado con el Sureste peninsular, sino que asumió desde muy pronto la capitalidad y referencia de la totalidad de la demarcación. No en vano era el enclave de mayor entidad, tanto económica como demográficamente, desde los tiempos de Ibn Mardanish ${ }^{16}$ y asentada por la administración almohade. Sólo una fisura, grande eso sí, en el aserto anterior.

${ }^{16}$ Ignacio GONZÁLEZ CAVERO, Una revisión de la figura de Ibn Mardanish. Su alianza con el reino de Castilla y la oposición frente a los almohades, "MMM", XXXII (2007), pp. 95-110. 
La erección del obispado de Cartagena en $1250^{17}$ hizo más por dibujar los límites exactos del nuevo reino que la propia intervención organizativa monárquica. Pero el núcleo cartagenero, al igual que el alicantino, no encontró mayores activos que los esfuerzos y anhelos de Alfonso X por asumir una importancia crucial en el Mediterráneo. Murcia se convirtió desde el mismo momento de la conquista cristiana en el referente indiscutido para propios y extraños, a pesar de que la cercanía de un puesto tan estratégico (cuando no más) como Orihuela, o la precisión de una defensa como la de Lorca o Mula, la convertían en un gigante con pies de barro. Será su importancia comercial la definitiva para que asegurase en el futuro su papel predominante y primordial, además sin discusión institucional en el seno de la demarcación.

Un hecho clave para entender esa referencia es que todos los núcleos van a intentar reproducir el modelo de la capital del Adelantamiento, arrastrados además por las redes económicas que sostenía el territorio, donde la ciudad del Segura era el nodo de su funcionamiento. Las redes sociales de los diversos enclaves del reino se tejían a la manera de Murcia, cuando no hubiera intentos (exitosos o no) de enlazar linajes locales de Hellín, Mula, Jumilla, Lorca o Cartagena con sus paralelos de la gran ciudad. Precisamente ésa es la cuestión que hace de la urbe capitalina la más compleja de estudiar en la demarcación, en tanto en cuanto supuso la gran excepción del conjunto territorial. Todo el engranaje militar y económico se movía a su derredor, un ejemplo excepcional de la percepción que se tenía en el siglo XV de ese hecho, al margen de la propia conciencia que el concejo murciano tenía de sí mismo, apoyando sus cartas como cabeça del regno ${ }^{18}$, y de una realidad que ya había dejado plasmada el propio Alfonso X en su testamento ${ }^{19}$. Durante el periodo donde los infantes de Aragón encarnaron el principal problema político en Castilla, y enmarcado en el enfrentamiento civil en el seno del reino de Murcia, una parte del regimiento de la capital llegó a insinuar su ofrecimiento a Alfonso V de Aragón. La oposición no vino de otro lado que de Orihuela $^{20}$, que veía perder su primacía como capital a su vez de la

${ }^{17}$ Una excelente sistematización de este proceso de asiento y configuración eclesiástica en $\mathrm{J}$. TORRES FONTES y A.L. MOLINA MOLINA, La Diócesis de Cartagena y su catedral (1250-1805). Incorporación del Reino de Murcia y restauración del obispado de Cartagena, en Huellas. Catálogo de la exposición, Murcia, 2002, pp. 32-57, aunque entre otros muchos estudios, es interesante el planteamiento genérico que realiza el profesor TORRES FONTES en Tratados, pactos y convivencia cristiano-musulmana en el reino de Murcia (1243-1266), "Murgetana", 94 (1997), pp. 43-53.

${ }^{18} 1439$, diciembre, 19, Murcia. "Honorables señores e amigos, justiçia e jurados de la çibdad de Orihuela. El conçejo, alcaldes e alguasil, regidores, caualleros, escuderos e ommes buẹnos de la muy noble çibdad de Murçia, cabeza de regno, vos enbiamos..." Archivo Municipal de Orihuela (en adelante AMO). Libro 23. Documentos sueltos. Acerca de la referencia inexcusable de la ciudad de Murcia hacia la demarcación que le da nombre, véase M $^{\text {a }}$ Llanos MARTíNEZ CARRILLO, Revolución urbana y autoridad monárquica en Murcia durante la Baja Edad Media (1395-1420), Murcia, 1980, pp. 196 y ss.

${ }^{19}$ Ballesteros Beretta, Antonio: Alfonso X el Sabio, Murcia, 1984, p. 1.051.

${ }^{20}$ Juan Antonio BARRIO BARRIO y José Vicente CABEZUELO PLIEGO, La defensa de los privilegios locales y la resistencia a la centralización política en la Gobernación de Orihuela, "Anales de la Universidad de Alicante. Historia Medieval", 13 (2000-2002), pp. 9-42. 
Gobernación a la que también le daba nombre. Una de las teorías más plausibles a la hora de plantear el cambio de lengua en la ciudad alicantina en el XVII, aparte del propio prestigio lingüístico adquirido en esas fechas por el castellano, es la irradiación cultural y económica de Murcia sobre toda la Vega Baja, independientemente del estado de recelo perenne oriolano hacia lo procedente desde tierras murcianas, de manera muy posible como rasgo identitario respecto al exterior.

Fue la residencia casi habitual del adelantado mayor a lo largo de la Baja Edad Media; y el logro de la regiduría murciana por el medroso Alonso Fajardo, alcaide de Lorca, no puede ser visto con otros ojos que con los de haber conseguido el control interno de la capital. El conjunto de maniobras políticas de don Juan Manuel en la primera mitad del siglo XIV, el de los distintos Fajardo durante el XV y el definitivo del I marqués de los Vélez (donde los sucesos de Comunidades se muestran clarificadores en este sentido), estuvieron dirigidos a dominar políticamente la ciudad de Murcia, con la constancia de que su control permitía la sujeción de la globalidad del territorio.

Pero esa complejidad a la que he hecho referencia al comienzo de este subapartado tiene su explicación en el mismo momento en que las plazas de Cartagena y Lorca suponían la articulación completa del territorio más cercano a la costa. La primera por cuanto asumía el carácter mediterráneo de la demarcación (y por extensión de Castilla), y la segunda por su importancia geoestratégica en el paso del Sur al Levante peninsular. Estos factores llevaron a que realmente fuese la supremacía política del obispo de Cartagena (residente en la ciudad de Murcia) y del adelantado mayor (también como capitán mayor de guerra) la que sustituyó a la propia de la ciudad de Murcia. El hecho de que el puerto cartagenero fuera (y es) el mejor puerto del Mediterráneo Occidental derivó en que asumió casi todas las competencias en asuntos marítimos, incluidos los problemas por asaltos corsarios ${ }^{21} ; \mathrm{y}$ me estoy refiriendo a momentos en que pertenecía al patrimonio real, y no concretamente en los años de propiedad de don Juan Manuel $^{22}$ o de don Pedro Fajardo y Quesada y de don Juan Chacón.

El caso de Lorca es igualmente intrincado. Su importancia militar como llave del reino frente a Granada, la convirtió desde el mismo momento de la conquista en la plaza fundamental para el sostenimiento del territorio. Si en Tudilén la Corona castellana se la reservó como enclave de futuro control $^{23}$, tal y como he mencionado con anterioridad, la fijación de la frontera

\footnotetext{
${ }^{21}$ Un estudio de compendio acerca de la importancia de Cartagena como enclave estratégico a lo largo del periodo medieval (en su totalidad) y altomoderno, fue realizado por David MUNUERA NAVARRO en su tesis doctoral, Musulmanes y cristianos en el Mediterráneo. La costa del Sureste peninsular durante la Edad Media (ss. VIII-XVI), defendida en la Universidad de Murcia, en febrero de 2010.

${ }^{22}$ J. TORRES FONTES, Don Juan Manuel, señor de Cartagena (1313-1347), “Anexos a Cuadernos de Historia de Éspaña. Homenaje a don Claudio Sánchez-Albornoz", IV (1986), pp. 35-57.

${ }^{23}$ Jaime CARUANA GÓMEZ DE BARREDA, Cómo y porqué la provincia de Murcia pasó a ser de reconquista castellana, "MMM", VII (1981), p. 69.
} 
militar con los nazaríes y las posibilidades bélicas de la imponente fortaleza de la por entonces villa hicieron el resto. La referencia territorial de lo que era el segundo núcleo de mayor peso específico en el reino (de hecho, el paralelo con Baza y Vera al otro lado) no esperó ${ }^{24}$. La formación de su extenso alfoz desde el mismo momento de la presencia del rey Sabio en el enclave (1257), configurado como un término jurisdiccional concejil de frontera al más puro estilo tradicional castellano, fue progresivo a lo largo de los siglos siguientes. Incluso en los años finales de la guerra de conquista, en 1488, los Reyes Católicos le concedieron la última gran donación territorial en el seno del reino granadino, las villas de Huércal y Overa $^{25}$, situadas en el Bajo Almanzora y cubriendo un extenso pastizal que supuso el objeto de un largo pleito en el XVI entre Vera y Lorca.

El papel como referente fronterizo claro, no sólo en el plano físico sino en el institucional, no hizo otra cosa más que crecer al amparo de encarnar la vanguardia de Castilla en el límite oriental frente a los nazaríes. Las alusiones de la Corona a la línea de delimitación con los musulmanes granadinos eran claras: "de Lorca a Tarifa". Dos ejemplos que evidencian lo que suponía para los habitantes a un lado y otro de la frontera en tanto que muestran de manera meridiana que Lorca era la referencia inexcusable en todo el sector. El primero queda marcado por el reconocimiento del resto de núcleos fronterizos de la importancia que había asumido la ciudad en todos los asuntos concernientes a este plano de relaciones. Se trata de un caso de 1463 expuesto por la encomienda santiaguista de Caravaca, situada al Norte, al concejo de Lorca acerca de la manera de actuar ante un caso de propiedad dudosa por la huida de un cautivo desde Galera con un caballo; la cuestión planteada era la pertenencia legal del equino. La contestación de la ciudad se vinculaba a la devolución del jumento según costumbre ${ }^{26}$. Respondía la jurisprudencia fronteriza protagonizada en este caso por la autoridad reconocida en este plano para el concejo de Lorca. El otro ejemplo se localiza una vez se ha conquistado Granada y en el contexto local de la ciudad de Vera en 1496, recién repoblada. En una alusión al territorio murciano se refieren a él como el "reino de Lorca e Murçia" " No cabe la interpretación de insertar a la Ciudad del Sol en la demarcación murciana, sino que es claramente una mención clarificadora tomándola como referencia espacial. Se asume como el paralelo de la propia Vera, al igual que se tenía el contacto con

\footnotetext{
${ }^{24}$ Sobre el núcleo en su extensión, y los particulares acerca de la organización territorial, en mis monografías Lorca: ciudad y término (SS. XIII-XVI), Murcia, 1994, y Un concejo de Castilla en la frontera de Granada: Lorca 1460-1521, Granada, 1997.

${ }^{25}$ J.F. JIMÉNEZ ALCÁZAR, Huércal y Overa: de enclaves nazaríes a villas cristianas (12441571), Huércal-Overa, 1996.

26 "Señores e amigos, vuestra carta vimos en que, en fecto, seruis que vino ende un catiuo con un cauallo de Galera. E que vos seruiesemos la costumbre e manera que se deue tener. A nos paresçe que vosotros señores, deueys mandar desferrar el catiuo e se vaya libre, e mandar restituir el cauallo, quel cauallo no se deue perder, pues que fue furtado o por el tomado". Archivo Histórico Municipal de Lorca (en adelante ÀHML). Cartulario 1463-64, f. 8r.

27“Ansimismo se remato la taverna desde San Miguel en un año en Miguel Asnar, a VIII maravedies del reyno de Lorca e Murcia..." Archivo Municipal de Vera. Libro 1A, f. 23r. Ya aludí a este hecho en Lorca: ciudad y término (ss. XIII-XVI, Murcia, 1994, p. 212.
} 
Baza. Y este proceso no se extinguió en este punto. Durante las amenazas de 1515 por parte de las flotas berberiscas y turcas en la costa, y asumiendo la ciudad de Murcia que su competencia era la defensa de Cartagena y del Mar Menor ("la albufera del Cabo de Palos"), será Lorca la encargada de aportar huestes para la defensa de la costa veratense, según había pedido el conde de Tendilla como Capitán General del Reino de Granada ${ }^{28}$, hecho ahondado tras el terremoto de 1518. Una aportación más en ese sentido. La sublevación morisca de 1568 favoreció el antiguo carácter de ciudad-base militar. El socorro prestado por la milicia concejil lorquina para levantar el cerco de Aben Humeya en septiembre de 1569 será reconocido en adelante por las autoridades veratenses; de hecho, aún hoy, el 25 de septiembre es festividad local en Vera, día de San Cleofás.

En ese sentido, la proyección de la ciudad hacia el Poniente una vez reabierto el Camino Real después de 1488, hizo que Lorca aumentase en progresión geométrica ese carácter referencial. Es el mismo caso que ocurrió con Cartagena una vez volvió a patrimonio real ${ }^{29}$ con la apertura de los intereses marítimos mediterráneos hacia el Magreb desde los mismos finales del XV.

Como puntualización final, hay que reseñar que es muy indicativa la consciencia que tenía la Corona castellana de la realidad territorial del reino murciano. La implantación del adelantado mayor por Alfonso X fue todo un acto de intenciones. Y mucho más representativo resultará la llegada de los corregidores después de 1478, ya que serán delegados reales de Murcia y Lorca (también de Cartagena tras 1503), siendo el sistema de corregimiento compartido habitual para la uniformidad territorial utilizado con otros lugares comarcanos, tales como lo reducido para el patrimonio real del marquesado de Villena con posterioridad a $1480^{30} \mathrm{o}$ toda la zona oriental granadina a partir de $1492^{31}$, buscando en cualquier caso actuaciones de centralización y control de extensas demarcaciones en una única referencia política. La red de autoridad y potestad de los tres principales núcleos del reino lograba colocar bajo una misma directriz política la voluntad real canalizada por la vara de la justicia de los distintos corregidores, incluso frente a las decisiones de los adelantados (evidenciada claramente durante los sucesos de Comunidades).

${ }^{28}$ AGS. Cámara de Castilla. Diversos, 44, 6.

${ }^{29} \mathrm{~J}$. TORRES FONTES, La reincorporación de Cartagena a la Corona de Castilla, "Anuario de Historia del Derecho Español", L (1980), pp. 327-352.

${ }^{30}$ Excelente el estudio de Jorge ORTUÑO MOLINA sobre el particular en su monografía Realengo y señorío en el Marquesado de Villena. Organización económica y social en tierras castellanas a finales de la Edad Media (1475-1530), Murcia, 2005, pp. 141 y ss.

${ }^{31}$ Juan GRIMA CERVANTES, El corregimiento de Vera-Baza antes del año 1500, "Roel", 7-8 (1986-97), pp. 55-82. De todas formas, desde el momento en que el corregidor fue contemplado por la Corona castellana, y la referencia es Enrique III, como un elemento básico para el ejercicio del poder central, esta política de unificación institucional era normal, caso de las villas santanderinas ya en el periodo de la regencia de doña Catalina (Archivo'Histórico Nacional. Nobleza. Osuna. $C^{a} 1.788, n^{\circ} 02-01$. Agradezco a Víctor Muñoz Gómez la referencia). Sobre el particular, y en un sentido más global, véase el estudio de Emilio MITRE FERNÁNDEZ, La extensión del régimen de corregidores en el reinado de Enrique III de Castilla, Valladolid, 1969. 


\section{3. ...y Aragón}

Si Vera representó desde la ocupación cristiana de Lorca, la mayor y mejor posición nazarí frente a Castilla, Orihuela será a partir de Torrellas la referencia territorial aragonesa indudable para castellanos, granadinos y propiamente valencianos ${ }^{32}$. No habrá tanta complejidad como en el territorio murciano, ya que las referencias en el territorio meridional del rey de Aragón se concretaban en la ciudad oriolana. Hay que partir del mismo momento en que las autoridades del enclave alicantino toman conciencia de su importancia y de la prestación de servicios al Rey Justo durante la guerra con Castilla de finales del XIII. La caída de Lorca en manos de Jaime II conllevó una capitulación muy beneficiosa para el concejo lorquino, pues conservaría todos los privilegios además de pasar a recibir unas atenciones específicas de la Corona (recordemos que buscaba su expansión por la fachada mediterránea y Lorca la proporcionaba). Las protestas de Orihuela al monarca no se hicieron esperar; con motivo del reconocimiento de los caballeros alforrats en Lorca, los oriolanos reclamaron al rey el mismo trato ${ }^{33}$. Los acontecimientos de 1304, donde Orihuela quedó como pieza clave de la soberanía en el sector, dieron paso a la encarnación de la villa como referencia indispensable para el ejercicio y reconocimiento de la autoridad aragonesa en la zona. La Guerra de los Dos Pedros abundó en el proceso, ya que el terrible cerco al que fue sometida, no hizo más que remarcar el deseo identificador del justicia y de los jurados como expresión última del conjunto social oriolano. Un hecho se iba a señalar por encima de los demás. Hasta 1329, las tierras que había conservado Aragón quedaban señaladas como Ultra Sexonam, sin mayores alusiones referenciales que la propia mención al conjunto del territorio. Pero la concesión al infante don Fernando del marquesado de Tortosa con un extenso señorío en tierras alicantinas, Orihuela incluida, hizo que profundizase más la importancia del consell oriolano desde el mismo momento en que quedó exento de la Procuración General de Valencia y se constituyó una procuraduría específica en la Vega Baja (cuyo titular sería nombrado, lógicamente, por el infante). La vuelta al señorío real en 1363 derivó en una doble maniobra de El Ceremonioso, pues concedió un privilegio vital para los oriolanos, y era la no enajenación futura del patrimonio de la Corona, y en segundo lugar la elevación al rango de Gobernación General en 1366, también independiente de la de Valencia y de la que se hubiese constituido en Murcia

\footnotetext{
${ }^{32}$ Indispensable la consulta de la tesis doctoral de J.A. BARRIO BARRIO sobre el núcleo a lo largo de los dos siglos bajomedievales: El ejercicio del poder en un municipio medieval: Orihuela, 1308-1479, Alicante, 1993. De este trabajo, resultó posteriormente un excelente trabajo monográfico sobre el funcionamiento institucional del consell oriolano: Gobierno municipal en Orihuela durante el reinado de Alfonso V, 1416-1458, Univ. Alicante, 1995.

${ }^{33}$ M.T.FerRER I MALlol, Organització $i$ defensa d'un territori fronterer. La Governació d'Oriola en el segle XIV, Barcelona, 1990, pp. 352-353.
} 
en el caso de que Enrique de Trastamara cumpliese su promesa durante la guerra civil con su hermano Pedro I de Castilla ${ }^{34}$.

No obstante, la fragmentación del reino a comienzos del XIV no se tradujo en el plano institucional eclesiástico, y el conjunto de la Vega Baja continuó en manos del obispo de Cartagena, leamos pues Castilla y, en consecuencia, reino de Murcia. El problema se agravó durante el enfrentamiento entre castellanos y aragoneses a mitad de ese mismo siglo en la mencionada guerra petrista. La solución por parte de Pedro IV fue organizar la demarcación como Gobernación General en 1366. Con este paso, quedaba zanjada la posibilidad de una reunificación del antiguo territorio alfonsí y, por ende, la ponderación de Orihuela como el puntal básico de la autoridad monárquica en el Sur del reino de Valencia.

La complicación de la ciudad en los enfrentamientos internos del reino murciano, tanto en el momento entre Manueles y Fajardos, como posteriormente en el seno de esta última Casa, no derivó en ningún menoscabo de la posición y papel jugado por Orihuela dentro del territorio de su Gobernación.

Los recelos continuarán en las décadas y siglos siguientes, a pesar de que muchos linajes entraron a formar parte de las redes sociales de los principales municipios murcianos. La evolución de los acontecimientos durante las Germanías no hizo sino asentar un fenómeno progresivo desde la última década del siglo XV. La configuración de una ruta sur para la exportación de la lana granadina y murciana a través de los puertos de Cartagena y Alicante (sobre todo de esta última) por los comerciantes genoveses, y que arrancaba en Granada, pasando por Baza, Huéscar, Lorca, Caravaca y con capitalidad de negocios en Murcia, hizo que fuese el mercado el factor que terminó por engullir a Orihuela. Pero eso sucedió décadas después al objetivo cronológico del presente estudio.

\section{RELACIONES INTERREGIONALES Y CONTACTOS MUNICIPALES}

Se ha expuesto el papel constituido y asumido por todos los elementos institucionales (bajo el parámetro de poderes locales) tanto en Vera (Granada), Lorca, Murcia y Cartagena (Castilla) como en Orihuela (Aragón). Por sí mismas y cada una por separado encarnaron el protagonismo de la soberanía que representaban (como no podía ser de otra forma). Pero a la vez y de manera paralela tejieron unas relaciones específicas como entidades locales que revestían trato cotidiano entre comunidades que se precisaban, tanto en el plano económico (fundamentalmente por abastecimiento o simple intercambio), como en el demográfico (se constata en la documentación un interesante trasiego poblacional entre el reino de Murcia y la Gobernación oriolana en el

${ }^{34} \mathrm{~J} . \mathrm{V}$. CABEZUELO PLIEGO, En torno a la creación y funcionamiento de la Gobernación General de Orihuela, "Anales de la Universidad de Alicante. Historia Medieval", 7 (1988-89), pp. 159-180. Del mismo autor, aunque centrado en el proceso previo de la Procuración, véase Poder público y administración territorial en el reino de Valencia, 1239-1348. El oficio de la Procuración, Valencia, 1998. 
siglo $\mathrm{XV}^{35}$, amén de lo que supondrá la apertura del proceso repoblador en Vera tras la conquista ${ }^{36}$ ), pero sobre todo por razones de índole fronteriza, donde las presas y los cautiverios estarán en el fondo de buena parte de las misivas y contactos institucionales.

La complicación radicaba no sólo en la diversidad de competencias jurisdiccionales, incluso en el seno de las propias demarcaciones, sino que sobre todo revestía la relación un trasfondo que iba más allá de la propia dinámica del contacto humano. El creciente nacionalismo castellano y valenciano (en este caso, a pesar de que desde el otero murciano se identificase a los de Orihuela como los catalanes) terminaba siendo una minucia entre cristianos cuando se comparaba con el encuentro (o desencuentro) entre cristianos y musulmanes. En realidad, el contacto terminó siendo productivo para todos, individuos e instituciones, menos en el caso de las víctimas cautivadas. Pero esas relaciones guardaban aún un sustrato mucho más interesante de analizar, y era la de los mecanismos físicos utilizados para la comunicación. El idioma usado se configuró como un elemento reflejo de las intenciones, de la costumbre y de la idiosincrasia de cada uno de los factores que jugaron algún papel en los actos comunicativos. Y evidentemente, fue la lengua manejada por los verdaderos protagonistas del traspaso informativo la que definía de manera clara a individuos e instituciones. Es aquí donde el mensajero pasaba de ser un simple correo a representar él mismo competencias diplomáticas, ya que no sólo se trataba de asuntos entre concejos, consells o aljamas, sino que asumía papeles de representante de soberanía. Puede parecer a primera vista que es un aserto muy arriesgado. Pero basta con observar la respuesta de esos enviados ante casos de resolución de cautiverios para comprender que un buen final comportaba el mantenimiento de treguas o de las buenas relaciones interregionales. Fue la propia dinámica fronteriza la que generó instituciones específicas para que resolvieran estas tesituras en ocasiones enrevesadas. Los alfaqueques y ejeas tenían la función esencial de rescatar cautivos mediante el trato diplomático ${ }^{37}$, reconocidos así por todas las

${ }^{35}$ J.A. BARRIO BARRIO, Inmigración, movilidad y poblamiento urbano en un territorio de frontera. La Gobernación de Orihuela a fines del Medievo, "Revista d'Història Medieval", 10 (1999), p. 217. 1994

${ }^{36}$ J.F. JIMÉNEZ AlCÁZAR, El libro de repartimiento de Vera. Estudio y edición, Almería,

${ }^{37}$ Existen diversos estudios, algunos de ellos ya clásicos, de esta institución eminentemente fronteriza: J. TORRES FONTES, Notas sobre los fieles del rastro y alfaqueques murcianos, "Miscelánea de Estudios Árabes y Hebraicos", 10 (1961), pp. 89-105, y Los alfaqueques castellanos en la frontera de Granada "Homenaje a D. Agustín Millares Carló", Las Palmas de Gran Canaria, 1975, pp. 99-116. José Énrique LÓPEZ DECOCACASTAÑER, Esclavos, alfaqueques y mercaderes en la frontera del mar de Alborán (1490-1516), en El Reino de Granada en la época de los Reyes Catolicos, vol. II. Granada, 1989, pp. 205-233 (publicado anteriormente en Hispania, 139 (1978), pp. 275-300), centrado en las primeras intervenciones castellanas en el Magreb durante el XVI, al igual que el trabajo de Manuel GARCÍA FERNÁNDEZ, La Alfaquequería Mayor de Castilla en Andalucía a fines de la Edad Media. Los alfaqueques reales, en Estudios sobre Málaga y el Reino de Granada en el V centenario de la conquista, Málaga, 1987, pp. 37 54. M. ABAD MERINO, Exeas y alfaqueques: aproximación a la figura del intérprete de árabe en el periodo fronterizo (sS. XIII-XV), "Homenaje al prof. Estanislao Ramón Trives", Murcia, 2004, pp. 35-50, con un interés más focalizado en el plano de Historia de la Lengua. 


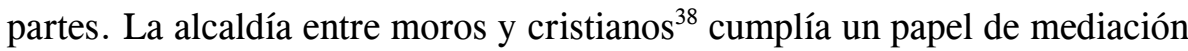
similar, con una competencia de arbitrio para evitar precisamente malentendidos entre los agentes fronterizos que pudieran dar lugar a enfrentamientos abiertos. Observemos pues todos estos elementos y factores de manera detenida, centrando el objetivo sobre las particulares (y en ocasiones peculiares) relaciones de los tres ámbitos de forma privativa antes de intervenir en el papel activo de mensajeros y enviados.

\subsection{El contacto castellano-aragonés}

La relación entre castellanos y aragoneses en el ámbito del Sureste peninsular marcó el surgimiento del espacio político de la Gobernación oriolana. Si con antelación a 1296 la urdimbre política del reino de Murcia incluía en el mismo plano a los concejos principales, que llegaron a firmar una hermandad en 1295 para la defensa del señorío de Fernando IV, menor de edad $^{39}$, y se mantendrá en el periodo de dominación aragonesa, el arbitrio de Torrellas abrió una profunda brecha que no se cerrará en ningún momento. Se había generado un abismo político definido por la lealtad de los pobladores respectivos a la naturaleza de su soberano correspondiente, e identificándose con una nación que respaldaba sus acciones y su propia idiosincrasia. Nos situamos en momentos de forja de identidades en el conjunto de Europa, donde la pertenencia a un lugar determinado le imprimía un sello de naturaleza que se prolongó hasta la formación del nuevo nacionalismo, culminación de las ideas ilustradas del XVIII, y los Estados Nacionales consecuencia del proceso anterior. Fue particular (por interesante) que el descubrimiento de una imagen de Nuestra Señora de Montserrat en Orihuela se produjera en 1306. En realidad todo fue fruto del reordenamiento poblacional desde la firma del acuerdo castellano-aragonés. Linajes arriba y abajo de la nueva linde, adscritos y leales al soberano castellano o aragonés respectivamente, y que condicionaron acciones diversas a causa de un enfrentamiento con hostilidades abiertas (el asedio de cuatro años a Lorca, o

${ }^{38}$ J.M. CARRIAZO ARROQUIA, Un alcalde entre los cristianos y los moros, en la frontera de Granada, en En la frontera de Granada, Sevilla, 1971, pp. 85-142 (reimp. facs. Granada, 2002). Luis SECO DE LUCENA, El juez de frontera y los fieles del rastro, "Miscelänea de Estudios Ârabes y Hebraicos", 7 (1958), pp. 157-140. También aludió al tema aunque centrado en el sector murciano J. TORRES FONTES, El alcalde entre moros y cristianos del reino de Murcia, "Hispania". LXXVIII (1969), pp. 55-80. De manera más reciente, existen también referencias diversas (Alfonso CARMONA ĠONZÁLEZ, La frontera: doctrina islámica e instituciones nazaríes, en Actas del Congreso La frontera oriental nazarí como sujeto histórico (SS. XIII-XVI), Almería, 1997, p. 57; $\mathrm{M}^{\mathrm{a}}$ Magdalena MARTÍNEZ ALMIRA, A proposito del rescate de cautivos conforme a las fuentes musulmanas de época nasrí, "Anuario de Historia del Derecho Español". LXXIII (2003), pp. 457-495; sobre todo de José RODRÍGUEZ MOLINA, como Relaciones pacíficas en la frontera con el reino de Granada, en Actas del Congreso La frontera oriental $\mathrm{pp}$. $285 \mathrm{y} \mathrm{ss}$.), aunque de forma más extensa conviene mencionar el estudio de José Enrique LOPEZ DE COCA CASTANER, Los jueces de las querellas, "Edad Media. Revista de Historia", 11 (2010), pp. 173 201.

${ }^{39}$ Antonio BEnAVIDES, Memorias de D. Fernando IV de Castilla. Tomo II, RAH, Madrid, 1860, pp. 46-50. Al final, hay una nota de Diego Clemencín justificando el espacio en blanco que aparece en el documento, destinado para Orihuela. También se incorporó Cartagena después de formalizada la hermandad: p. 52 . 
el realizado a Mula desde 1298 hasta su levantamiento en agosto de 1304, con bastida incluida), no hacía presagiar a corto plazo unas relaciones fluidas ${ }^{40}$. El momento para comprobarlo no tardó en hacerse esperar, pues durante el retorno de la desdichada cruzada de Almería, los desmanes cometidos por lorquinos y murcianos a las tropas que volvían por tierra hacia territorio de Jaime II, leamos Orihuela como enclave situado más al sur, fueron permanentes.

Pero la vecindad obliga a la relación fluida, sobre todo con intereses comunes, como lo eran los comerciales mediterráneos. Cierto es que coincidió con dos factores exógenos, y que terminaron por condicionar de manera notable ese desarrollo en los inicios del siglo XIV. Por un lado la presencia de don Juan Manuel flanqueando todo el sector aragonés desde el territorio conquense hasta la costa centralizada por su ciudad costera (Cartagena), y por otro, y en sentido mucho más general, por la dinámica no favorable global en Occidente. Los factores endógenos de cada uno de los territorios a su vez no propició otro tipo de relaciones que no fuesen estrictamente los de supervivencia: Orihuela entrando en un patrimonio nobiliario (infante don Fernando, recordemos) y los núcleos murcianos insertos en una profunda guerra civil, además de soportar un proceso de despoblación intensa. De hecho, fue promoción del propio noble castellano el último proyecto repoblador de Lorca en $1336^{41}$.

Pero para entonces ya existían implicaciones oriolanas en sucesos de la frontera, donde los cautiverios eran cotidianos ${ }^{42}$. Las cabalgadas nazaríes no eran extrañas y la necesidad de defensa común entre castellanos y aragoneses se hizo obligada. Las hostilidades durante la Guerra de los Dos Pedros fueron un oasis en este sistema de relación, en tanto en cuanto aquí entraba en juego el interés específico de ambas Coronas de manera directa, sin mediación posible de los poderes locales a excepción de la participación en las acciones bélicas de sus respectivas huestes concejiles.

De todas formas, y al margen de este suceso básico para entender parte de la idiosincrasia de Orihuela con respecto a lo que podía esperarse de Murcia (empezando por los habituales roces por cuestiones de vecindad física), fueron las relaciones establecidas con Cartagena y con Lorca las que más nos interesan en este momento. Eran comunicaciones establecidas en un mismo plano, donde la casuística de los temas se restringía casi exclusivamente a asuntos de frontera (cautiverios, presas en la costa...). Pero aquí es donde entraba en juego uno de los factores más definitivos en el tipo de contactos

\footnotetext{
${ }^{40}$ Sobre todo el panorama acerca de la intervención aragonesa en el reino de Murcia durante los años finales del XIII y primeros del XIV, véase el profuso estudio de M.T. FERRER I MALLOL, Entre la paz y la guerra. La Corona catalano-aragonesa y Castilla en la Baja Edad Media, Barcelona, 2005.

${ }^{41}$ J. TORRES FONTES, Tercera partición del repartimiento de Lorca, "Murgetana", LXXIII (1987), pp. 33-46. En la reedición del repartimiento lorquino, el profesor murciano ubicó en cuarto lugar a este proyecto de don Juan Manuel (Repartimiento de Lorca, Murcia, 1994).

${ }^{42} \mathrm{~J} . \mathrm{V}$. CABEZUELO PLIEGO El negocio del rapto en la frontera de Orihuela a principios del siglo XIIV, "MMM", XXI-XXII (1997-1998), pp. 43-58. M a M. MARTínEZ AlMIRA, ob. cit.
} 
existentes: el papel del Adelantado Mayor del Reino de Murcia. Quedaba reconocido por los diversos poderes locales, y no sólo en el caso de los concejos murcianos, sino por el consell de Orihuela, que lo veía, no sin razón, como interlocutor válido para cuestiones judiciales. De hecho, era el referente obligado que tenía que decidir en un momento determinado; incluso en ocasiones bastaba con que estuviese informado. Esta peculiar relación no debe extrañar, ya que se realizaba en un plano distinto al que se mantenía con el concejo de Lorca, pongamos por caso, pues si en éste era una red entre comunidades locales, aquél lo era entre instituciones de carácter territorial: Adelantado Mayor como encarnación judicial del poder central (y él mismo como poder territorial a través de su patrimonio, bien con Manueles bien con Fajardos), y Orihuela asumiendo legitimación real para resolver cuestiones con un poder ajeno a su propio reino.

El sostenimiento de la estructura defensiva frente a Granada también configuró la relación entre oriolanos y murcianos (lorquinos y propiamente murcianos capitalinos). Ante la posibilidad de ataques nazaríes, las autoridades murcianas reclamarán habitualmente la colaboración en el sufragio económico del sistema de escuchas y atalayas en la vanguardia (desde Moratalla hasta Águilas, en la costa). Estas solicitudes se hacían en el ámbito de la normalidad fronteriza, y no precisaba de contactos diplomáticos de altura entre autoridades suprarregionales. Se trataba de la versatilidad de un enemigo común; en ocasiones este sistema no funcionaba así, por la sencilla razón de que existía una gran complejidad en las relaciones internas de todos los agentes (incluso en el seno del propio reino murciano, donde no era extraño en momentos políticos difíciles que adelantado y alcaides o comendadores situados en vanguardia no sostuvieran una posición monolítica que hubiese frenado, o amortiguado, la cabalgada nazarí).

Por lo tanto, y al margen de las relaciones comerciales (incluso con instituciones privativas que restringieran lógicamente el contrabando, como el alcalde de las cosas vedadas), los contactos entre Castilla (murcianos) y Aragón (oriolanos) se circunscribieron al canal entre entes paralelos, de cualquier forma y manera, especializada la correspondencia con la capital por asuntos de tipo vecinal, con Cartagena por asuntos marítimos, con Lorca por cuestiones fronterizas frente a Granada (este eslabón es fundamental en este presente estudio, por lo que volveré sobre él), y con el adelantado mayor como interlocutor válido para resolver asuntos de tipo judicial interregionales, donde las autoridades oriolanas precisaban de una decisión concreta y legitimada.

\subsection{El contacto castellano-nazarí}

Desde el mismo momento de la existencia de la frontera castellanonazarí podemos decir que se trata de un clásico historiográfico. No sólo hay que observar las obras de investigación del siglo XX, con grandes maestros conocidos por todos, caso de Carriazo Arroquia, Seco de Lucena o Torres Fontes, sino también de investigadores pertenecientes a distintas generaciones 
desde los años 70 y 80 del pasado siglo. Debemos aludir a estas relaciones con la óptica de quienes las asentaron como razón y legitimación de sus posiciones de poder socio-político. Dejando de lado esos contactos bélicos, bien de tipo abierto (guerra declarada por agotamiento de plazo de treguas) o bien de carácter particular (la guerra chica, vergonzante, o atenuada a la que aluden algunos de los maestros mencionados), la cercanía y los inevitables roces cotidianos entre los individuos de ambos lados, además de la más que humana actividad comercial (el intercambio forma parte antropológica de nuestra especie), supusieron el nudo gordiano de los relaciones habituales entre las instituciones cristianas de la Murcia castellana y las islámicas de la Vera nazarí.

Este permanente trato ha generado un debate en el seno de los historiadores que hemos dedicado en algún momento nuestra atención a la Frontera de Granada. Por un lado queda la posición, muy loable por bondadosa, de unas relaciones francas y de cotidiano buen entendimiento, con la excepción marcada en los puntuales momentos de guerra abierta. Por otro, quienes interpretamos esas relaciones como de obligada vecindad que busca la supervivencia, independientemente de cómo se logre. La obsesión al cautiverio fue permanente en los sectores de mayor exposición a ese peligro, caso de las posiciones de vanguardia (y esta demarcación era bastante profunda hacia territorio amigo) y de las costeras mediterráneas, hecho que no se mitigará en estas últimas zonas hasta bien entrado el siglo XVII por la presencia de naves turcas o sobre todo magrebíes. Este factor es suficiente para lograr extraer un contexto fronterizo hostil. De hecho, serán los asuntos de rescates, huidas o solución de cautiverios ilegales (según la costumbre fronteriza) los que supongan la mayor parte de las comunicaciones entre las autoridades de ambos lados de la frontera. Ya he aludido a las instituciones específicas con este fin, caso del alcalde entre moros y cristianos y del alfaqueque; me estoy refiriendo ahora al canal abierto entre comunidades locales que terminan siendo las que mayor interés suscitan.

La presencia de una amenaza común en los contornos, como por ejemplo fustas catalanas o francesas en las costas, hará que se realicen los avisos oportunos a las autoridades veratenses por el concejo cristiano de Lorca $^{43}$ existiendo contrapartida en el sentido contrario, es decir, avisos desde la plaza nazarí hacia la castellana ${ }^{44}$. Habría que plantearse si se trataba de una cuestión que buscaba más el mal menor, o la evitación de problemas posteriores, que el deseo de compartir destinos y o de un mantenimiento de buena vecindad. Se puede documentar incluso el pregón de una ordenanza sobre vedamiento de caza en el alfoz lorquino en la plaza de Vera ${ }^{45}$. En este

\footnotetext{
${ }^{43}$ AHML. Libro de propios 1473-74, 28 de junio de 1473, f. 1r. Se repite el libramiento por un hecho similar unos meses más tarde ( 8 de agosto, f. 3 r. y 23 de noviembre, f. $5 \mathrm{v}$.).

${ }^{44}$ Ibídem, 12 de noviembre de 1473 , f. 5v.

${ }^{45}$ Recogido por José GARCíA ANTÓN (Cautivos, canjes y rescates en la frontera entre Lorca y Vera en los úttimos tiempos nazaríes, "Homenaje al prof. Juan Torres Fontes", Murcia, 1987, vol. I, p. 550), y mencionado por J. RODRÍGUEZ MOLINA (Relaciones pacíficas en la frontera de Granada..., p. 290).
} 
sentido, es necesario conocer el contexto concreto en las relaciones entre una ciudad aislada de su entorno por motivos políticos (no eran extrañas las firmas de treguas privativas entre determinados nobles y posiciones concretas nazaríes, o entre concejos, casos documentados en diversos momentos de la segunda mitad del siglo $\mathrm{XV}^{46}$ ). Se puede pensar, y no es arriesgado hacerlo por lógico, que las relaciones personales entre individuos de ambos lados fueron posibles; de hecho, el contrabando sólo será factible por la confianza que se precisa para este contacto comercial ilícito. Volveré sobre el particular.

Los cautiverios fueron, tal y como he mencionado, el asunto habitual que ocupaba las comunicaciones de Vera con los cristianos, y normalmente se llevaba a cabo mediante un canal abierto de forma permanente con la ciudad de Lorca, contemplada como el interlocutor válido para pasar los rastros, negociar con otros concejos murcianos e incluso con los aragoneses de Orihuela. Las noticias a Murcia ciudad llegaban a través de ese medio, e incluso el adelantado quedaba informado de la misma manera. Es muy interesante que las autoridades islámicas no reconocieran la figura del adelantado mayor como tal institución, sino que lo hacían a título particular según la expresión de su poder (caso de don Pedro Fajardo y Quesada). Era un reconocimiento parecido al que despertó Alonso Fajardo, alcaide de Lorca, entre algunos musulmanes. Se generó un mundo de frontera, mítico y mísero como el que más, y que encontró en los romances su expresión más dulce: las relaciones entre individuos enturbiaba la claridad de unos contactos institucionales preestablecidos o acordados por la costumbre.

\subsection{El contacto granadino-aragonés}

Por último, las relaciones entre la Corona aragonesa y el sultanato nazarí revistieron un carácter a priori indirecto, pues no había territorio fronterizo que compartir. Todo fue a través del mar o con el catalizador murciano, pero en realidad se trató de un entramado muy intenso de contactos a todos los niveles, teniendo como el ejemplo la obra referente por excelencia de la Dra. Salicrú para el siglo $\mathrm{XV}^{47}$. El hecho de que Orihuela fuera vista por el conjunto del reino valenciano como zona de frontera frente a los granadinos ${ }^{48}$ se explicaba desde el mismo momento en que la franja territorial que los separaba era de apenas $100 \mathrm{~km}$, tal y como hemos mencionado, y que además era ésta prácticamente una demarcación semi-vacía, lo que se traducía

${ }^{46}$ Estas relaciones particulares han sido buena parte de la base sobre la que fundamentó el profesor J. RODRÍGUEZ MOLINA la teoría acerça de las buenas relaciones habituales entre castellanos y nazaríes, no sólo entre personas sino entre núcleos concretos, caso de Jerez y Ronda, Montefrío y Alicalá, o Jaén y Cambil (Relaciones pacíficas en la frontera de Granada...., pp. 274 y ss.).

${ }^{47}$ Roser SAliCRÚ I LluCH, El sultanat de Granada $i$ la Corona d'Arago (1410-1458), Barcelona, 1998. Numerosos trabajos previos de la Dra. FERRER I MALLOL (v g. Organització $i$ defensa d'un territori fronterer. La governació d'Oriola en el segle XIV, Barceiona, 1990, o La frontera amb l'Islam en el segle XIV. Cristians i sarraïns al pais valencià, Barcelona, 1988, entre otros) completarían esta base desde la que ha de partir cualquier investigación sobre el particular.

${ }^{48}$ M.T. FERRER I MALLOL, La frontera amb l'Islam, 1988. 
en una pista limpia que permitía las idas y venidas sin mayores contratiempos (aunque más de uno tuvieron las mesnadas nazaríes a la vuelta, representando las principales batallas en campo abierto del sector, caso de Velillas, Cabalgadores, Nogalte, o la más famosa, la de los Alporchones).

No obstante, el contacto vendrá definido por dos factores: por la implicación de vecinos de algún núcleo de la Vega Baja bien cautivadores bien cautivados, o por las relaciones directas proporcionadas por la intervención marítima. El primer caso será más habitual, sin desdeñar lo segundo. Reduzco estos contactos al plano más concreto del sector oriental, dejando de lado las relaciones diplomáticas al más alto nivel entre los monarcas. Por lo tanto, y por meras razones de proximidad geográfica (lejanía en este caso), tendrán menos intensidad (que no importancia), que las dos anteriores. No obstante, la fluidez de la correspondencia fue notable entre las ciudad de Orihuela y Vera, y en ocasiones sin la mediación de los poderes castellanos, tal y como se trasluce de las misivas copiadas en los libros de actas del consell oriolano. Esa comunicación abierta en periodo de paz es lógica, pues la resolución de situaciones que precisaban una atención concreta, caso de los cautiverios, obligaba a un contacto directo y versátil. No se trata propiamente de "buenas relaciones" entre oriolanos cristianos y veratenses musulmanes ${ }^{49}$, que lo fueron coyunturalmente, sino de necesidad y de seguimiento de naturales reglas diplomáticas. En ningún tiempo ni en ninguna circunstancia se comienza una misiva de manera agresiva ni ofensiva si lo que se persigue es un entendimiento; más bien al contrario, utilizando en lo posible el epíteto excesivo y el eufemismo adecuado; de hecho, ¿no es ésa la base de la diplomacia?

\subsection{El contacto a tres bandas}

Seré breve en este apartado, pues se trata básicamente de exponer la realidad del contacto entre aragoneses y granadinos con la participación castellana. Pero de hecho, es el que mayor interés tiene para mi propósito, pues la intermediación de los poderes locales castellanos logra definir ese engranaje de competencias y legitimaciones superpuestas que concreta la organización espacial gestada durante estos dos siglos bajomedievales.

Las cartas remitidas desde la aljama veratense a las autoridades locales murcianas, bien a Lorca bien a Murcia (sobre todo a la primera), como interlocutoras reconocidas para que se inmiscuyesen en asuntos de cautiverios realizados por vecinos de otro reino cristiano, tiene su explicación en la complicidad que se presuponía en dos sentidos: por un lado, Vera se planteaba el entendimiento entre cristianos (Lorca y Orihuela, aunque de distinta jurisdicción y reino), y por otro, la constancia de la necesidad (obligación) comunicativa con el concejo paralelo en la frontera (Lorca), pues asumía que jugaba su mismo papel pero en el otro lado de la linde.

\footnotetext{
${ }^{49}$ M.M. MARTÍNEZ AlMiRA, ob. cit., p. 481.
} 
Este reconocimiento es fundamental.

La triangulación entre Vera, Lorca y Orihuela fue un hecho que paso a analizar, y que termina configurando una realidad organizativa del espacio y de definición política tan interesante, que objetiva el propio concepto manejado por aquellas instituciones y las gentes que las componían y representaban acerca de la legitimidad del poder central. El concejo, en abstracto, era un representante de la soberanía real, y como tal respondía y actuaba ante circunstancias que debían ser resueltas de inmediato (con la prudencia que debemos tener ante el propio concepto temporal de "inmediatez" en la gestión durante el periodo anterior a la revolución de las comunicaciones). Es muy interesante, de todas formas, la particular atención que pondrán las autoridades locales oriolanas porque las cuestiones relacionadas con estos cautiverios sean conocidas por el rey granadino, haciendo especial hincapié en tener abierto ese canal, por otra parte correspondido ${ }^{50}$.

A lo largo del siglo XV, tenemos diversos ejemplos que nos servirán para el propósito del presente estudio. Se conservan en el Archivo Municipal de Orihuela, y que nos han llegado a proporcionar incluso originales de misivas procedentes de la aljama de $\operatorname{Vera}^{51}$, con la fortuna de documentar también, siempre en ocasiones, la correspondencia cruzada. Existen rastros de ese paso por Lorca, aunque ciertamente parcos y sin mayor información que el simple registro por los gastos ocasionados ${ }^{52}$. No obstante, hago hincapié en esa relación particular entre los dos concejos cristianos, más cuando es Vera la que busca esa mediación específica de Lorca. La causa, por principal más que por única, hay que encontrarla en la posibilidad de la represalia directa. Para el musulmán de la franja oriental granadina, los cristianos más allá de los puntos acordados como fronterizos por el uso desde la mitad del siglo XIII (Fuente la Higuera o Cabeza de la Jara, por ejemplo), aparte de la referencia significativa de la ciudad murciana, el resto de núcleos, aun guardando su especificidad, eran tierras cristianas. No debemos perder esta perspectiva, pues la contemplación del otro se muestra vigente en todo momento, incluso después de las capitulaciones de 1492; el reconocimiento como monarcas de los Reyes Católicos por parte de los habitantes de las ta'as orientales en 1488 no varió en absoluto la percepción que unos y otros tenían de sí mismos y del contrario. Por esta razón, es importante que consideremos

\footnotetext{
${ }^{50}$ AMO. Libro 16, f. 80v.

${ }^{51}$ Analizada, traducida y transcrita por M. ARCAS CAMPOY y J.F. JIMÉNEZ ALCÁZAR en Una carta en la frontera de Granada: de la Vera nazarí a la capital de la Gobernación de Orihuela (año 879/1474), "Estudios de Dialectología Norteafricana y Andalusí", 10 (2006), pp. 81-92. La profesora Ma Magdalena MARTínEZ ALMIRA en $A$ proposito del rescate, ya realizó la misma traducción y transcripción, con algunas variaciones en la misma, hecho que nos ayudó en su momento a perfilar el documento en sí. El concienzudo análisis que realịó la Drá. Martínez Almira se centró en la cuestión del cautiverio más que en las propias relaciones existentes entre los tres poderes. Los menciona (p. 469), aunque de manera somera y adscrito al objetivo primordial de su estudio.

${ }^{52}$ Es el caso de esa misma carta en árabe conservada ẹ el archivo oriolano. En el libro de actas del concejo lorquino aparece que Abolax pasó por la ciudad murciana, registrando gasto por el mismo motivo (J.F. JIMÉNEZ ALCÁZAR, El hombre y la frontera: Murcia y Granada en época de Enrique IV, "MMM", XVII (1992), p. 83).
} 
las relaciones a tres bandas entre los tres núcleos como decisorios en los contactos institucionales, pero no como cuestiones individuales ni personales.

\section{MENSAJEROS Y DELEGADOS: EL FACTOR HUMANO}

Una vez visto todo el entramado de relaciones institucionales entre los tres ámbitos territoriales, de soberanía y culturales (en ningún momento olvidemos que se trataba de tres zonas con tres ámbitos lingüísticos distintos, por mucho que castellano y catalán fuesen lenguas romances, ya que había otras implicaciones de tipo político, sociolingüístico más bien), cabe ahora la oportunidad de aludir al factor humano que lo hizo posible. En efecto, las instituciones siempre la forman personas, individuos que dependiendo de su implicación y competencia marcarán el tipo de contacto posible entre los distintos entes. El reconocimiento de un mediador (llámese alfaqueque, lengua, ejea, mensajero, diplomático, enviado particular, etc.) por las partes no sólo favorecía el acto comunicativo sino que lo permitía.

Lo importante de estos individuos va a ser la legitimación con la que podían hacer y deshacer cuestiones, de manera que serán sus decisiones las que terminen por ejecutar voluntades políticas interregionales. En el caso de los diplomáticos enviados para firmar treguas, normalmente personas de altas dignidades, son (antes y ahora) representantes reconocidos como individuos a los que respalda el sistema. Pero en el caso de estos canales tan concretos, su mantenimiento se debía al carácter nominal de los individuos. Una cara, un personaje, una familia o un linaje... era tan decisivo como la procedencia de la naturaleza de cualquier vecino. Hay que considerar que nos movemos en un ámbito donde se conocía con mucha precisión a la mayor parte de la población de los diversos núcleos (si pertenecía al propio enclave o no, de qué familia, su adscripción territorial, en último término, si era forastero y de dónde). Pondero este hecho, ya que la influencia del factor quién se muestra decisiva en esta coyuntura.

Las formalidades para legitimar su papel una vez se presentaba el individuo en el ámbito de interlocución variaban según la calidad del asunto, pero lo habitual era la carta de creencia ${ }^{53}$. Lo interesante es cuando no se precisaba esa carta. Ese poder, en la acepción de documento acreditativo, es altamente representativo en su sentido más amplio, pues era la fórmula acreditativa para legitimar reconocimiento y actuación. Esa delegación se expresaba en la mayor parte de los contactos, caso de las treguas ${ }^{54}$ o de los negocios fronterizos, como mensajeros expresamente enviados para resolver

\footnotetext{
${ }^{53}$ Las cartas de creencia suponen un elemento en sí mismo, pues se asume que es la base de la delegación.

${ }^{54}$ Para la tregua de 1310, A. CARMONA GONZÁLEZ especifica la fórmula "un homne bueno, con nuestro poder" (ob. cit., p. 57).
} 
cuestiones no finalizadas después del trabajo de los alfaqueques ${ }^{55}$, por citar ejemplos extremos ya que cualquier mensajero las solía portar.

Las legaciones podían estar compuestas por varios individuos, condicionadas siempre por el carácter del negocio planteado. En este sentido cabe conceder la importancia ponderada al uso de la lengua para la fluidez en el acto comunicativo. La interpretación entraba como actividad fundamental: el enviado podía o no tener conocimientos lingüísticos de la parte a donde iba a realizar su encargo, de ahí que el intérprete específico, latente o no en la documentación, tenga su protagonismo. En este sentido, la existencia de auténticos políglotas como lo eran en algunos casos judíos, con nombre y apellido, es patente en la documentación, de manera que estamos condicionados a pensar que sus labores diplomáticas quedaban enmarcadas en el mismo plano que los delegados, aunque con un papel específico, concreto y bien delimitado. Pero también es cierto que resulta igualmente interesante el hecho de que existiesen mediadores con conocimientos propios. Llegado el caso, pudo emanar de esta cuestión el reconocimiento particular para la resolución del conflicto, como en el de determinados alfaqueques. En el caso de LorcaOrihuela podíamos pensar en una subyacente circunstancia de sesquilingüismo o bilingüismo pasivo, pero no en el de Orihuela-Vera o Lorca-Vera por razones evidentes. La llegada de cartas facilitaba en ese sentido la comunicación, ya que se pausaba la comprensión del mensaje y se facilitaba la respuesta. Pero de la misma manera, el idioma en el que se escribía nos resulta de interés, ya que predisponía a la hora de posicionarse en el momento de dirigirse al interlocutor. Por ejemplo, era normal que Lorca dispusiera de un escribano de lo morisco (a mitad del XV documentamos a Çafaz Díaz) ${ }^{56}$ para traducir las misivas llegadas desde el reino nazarí, o que el adelantado de Murcia se dirigiese a comienzos de ese mismo siglo en valenciano a Orihuela ${ }^{57}$.

Un hecho que ha suscitado una teoría sostenida hasta ahora es que Murcia precisaba de un traductor para las cartas llegadas desde Orihuela a comienzos de esa misma centuria a la que refiero las últimas notas ${ }^{58}$. Lo cierto es que, según el mismo documento atestigua ("e por quanto el conçejo de la villa de Orihuela enbio una carta de respuesta al conçejo desta çibdat de otra carta por el dicho conçejo a ella enviada (...) la qual vernia en catalan, la qual era menester de se tornar en castellano, porque el que auia de faser la

\footnotetext{
${ }^{55}$ Sobre este particular, y en concreto referido al factor cartas de creencia, véase las alusiones de M.M. MARTÍNEZ AlMiRA en su estudio citado A propósito del rescate de cautivos..., p. 461.

${ }^{56}$ Aparece en una carta del concejo de Lorca destinada al de Murcia en 1451. Publicada en el apéndice documental de J.F. JIMÉNEZ ALCÁZAR y M ${ }^{\mathrm{a}} \mathrm{M}$. ABAD MERINO, Fronteras lingüísticas durante la Baja Edad Media en el Sureste Peninsular: castellano, árabe y catalán en el reino de Murcia (ss XIII-XV), en "Actas de VII Estudios de Frontera". Islam y Cristiandad, siglos XII-XVI, Jaén, 2009, p. 421. Al mẹcionado judío traductor también lo localizamos realizando tareas de mensajería (Archivo Municipal de Murcia. Leg. 4292, 6).

${ }^{57}$ AMO. Libro 16, f. 53r.

${ }^{58}$ Pilar DÍEZ DE REVENGA TORRES, Estructura textual de unas cartas medievales, en Homenaje al prof. Lapesa, Murcia, 1990, pp. 115-116. También en Historia y Lengua en el reino de Murcia bajomedieval, "Estudios de Lingüística de la Universidad de Alicante”, 8 (1992), p. 96.
} 
respuesta la entendiese mejor"59), existía una precaución para evitar cualquier tipo de malentendido. Se precisaba un conocimiento específico y exhaustivo de lo que se leía y se contestaba en términos concretos y perfilados con el fin de que se solventase de forma correcta el asunto. Se entendía pues en Murcia el catalán y en Orihuela el castellano; lo que posiblemente no se hiciese bien sería escribir con garantías (en una coyuntura muy similar a lo que sucede hoy día, con todas las reservas que queramos ponerle al aserto), o incluso entender con todos los matices los contenidos escritos; de ahí la importancia de la expresión "mejor" en el acuerdo. Sigo vinculando la existencia del canal comunicativo a los comportamientos individuales (al margen de lo institucional) a un lado y otro de la frontera, ya que la vecindad de Orihuela con la ciudad de Murcia pudo desgastar la relación, hecho que no existió con Lorca debido a la lejanía, restringidos los contactos a los asuntos fronterizos con Granada.

\subsection{Nuestro mensajero}

El individuo escogido para ir como delegado, bien con una carta de creencia bien con una misión concreta (caso de un rescate de cautivos), tenía que poseer ciertas dotes personales de trato humano y también de reconocimiento de autoridad, tal y como se ha aludido con anterioridad ${ }^{60}$. No obstante, es muy importante saber el asunto que se planteaba con el fin de exponer la calidad de la persona. En el caso de Vera y del asunto de los musulmanes capturados en 1474, la persona remitida a Orihuela para afianzar el asunto fue Abolax. Desconocemos exactamente de quién se trataba, pero sí que sabemos que era persona principal habida cuenta que en el repartimiento veratense realizado por los castellanos en la década de 1490 aparece su nombre como topónimo $^{61}$, lo que indica con precisión que se trataba de una persona principal. Cuando en ese mismo asunto, Vera solicitó la mediación de Lorca para la correcta resolución del problema, los que marchan acompañando al enviado nazarí (que no mensajero, por mucho que porte la misiva), fueron dos regidores los que acompañaron al musulmán, Juan Ponce y Diego de Otón ${ }^{62}$. Aún no se había producido la reforma de Cabrero en 1490, donde en la ciudad se imponía el sistema del regimiento vitalicio, pero un regidor asumía la

\footnotetext{
${ }^{59}$ Archivo Municipal de Murcia. Acta capitular 1415-16, sesión 15 de febrero de 1416, f $129 v$. El marcado es mío, por cuanto el adverbio "mejor" resulta decisivo, ya que hay que asumir que el lector tenía cierto grado de comprensión lingüistica de catalán. Continúa el acuerdo: "Por ende ordenaron e mandaron al dicho Bartolome Gallante, su jurado clauario, que faga trasladar la dicha carta de catalan en castellano e que de al omme que la tresladare dies e ocho maravedies de tres blancas el maravedi, que son de dos blancas veynte e siete maravedies. Que le sean resçebidos en cuenta".

${ }^{60}$ Sobre los mensajeros en la frontera murciano-granadina, véase Francisco VEAS ARTESEROS, Lorca, ciudad de frontera, "Lorca. Pasado y presente", Murcia, 1990, vol. I, p. 216.

${ }^{61}$ J.F. JIMÉNEZ AlCÁZAR, El libro de repartimiento de Vera, p. 94. Los bienes de este individuo fueron concedidos a Beatriz de Aroca, viuda de Gonzalo López, montero de Fernando el Católico.

${ }^{62} \mathrm{AMO}, \mathrm{A}-32$. Documentos sueltos.
} 
legitimación del poder local, más cuando se trataba de un momento en donde el poder territorial del adelantado Pedro Fajardo y Quesada había alcanzado un nivel desconocido para un noble en el reino de Murcia. Ni don Juan Manuel logró en sus mejores momentos, políticamente hablando, un grado de dominio y control sobre la demarcación tan alto. En ese sentido es donde deseo ubicar la importancia de los emisarios: el respaldo lo ofrecía el concejo en sí mismo, como puntal indiscutible para las cuestiones fronterizas, siempre bajo la directriz de un concejo realengo referencia territorial. Es tiempo de recordar los diversos privilegios de la década de 1460 al municipio lorquino de no enajenación del patrimonio real, ofrecidos tanto por Enrique IV como por el Príncipe don Alfonso durante las disputas sucesorias coetáneas a la Farsa de Ávila ${ }^{63}$. El concejo, como institución, se erigía claramente en el representante de la autoridad monárquica traducida al ámbito de las relaciones fronterizas, léase relaciones interterritoriales de distinta soberanía a la propia. Un suceso analizado por R. Salicrú nos ofrece un espléndido ejemplo de lo referido. En 1427, Jacob Israel, mensajero enviado por el rey nazarí hacia Aragón, cruzó las tierras murcianas al menos en cuatro ocasiones a lo largo de ese año. En uno de esos desplazamientos, y portando el judío algunos presentes para los reyes aragoneses (don Alfonso y doña María), los recaudadores de impuestos fronterizos establecidos en Lorca quisieron fiscalizarle la carga. Fue defendido por el adelantado Alonso Yáñez Fajardo II y por los regidores lorquinos, que lograron que "los embargos por los arrendadores de aquexa ciutat en el dito presente feytos se quitiessen", escoltándolo hasta tierras de Aragón y ordenando "a los ditos arrendadores e almuxarifes que no lo toquassen, e assin se fizo". Lo más interesante fue que se expidieron cartas de agradecimiento desde la Cancillería real aragonesa al adelantado murciano, al rey de Castilla y al concejo de Lorca ${ }^{64}$. La ubicación del concejo en la misma referencia que el resto de poderes central y territorial, en este caso en el particular local, explica completamente el papel jugado por la ciudad en el contexto fronterizo.

Los que iban y venían arriba y abajo de la frontera generalmente eran los mismos individuos, ya que el carácter de su reconocimiento como interlocutores para las partes era fundamental, hecho que no admitía grandes variaciones para evitar tener que iniciar desde el comienzo el proceso de confianza para el acto comunicativo. Es el "apreciado caballero que posee el poder para hablar" ${ }^{\prime 2}$, y no sólo porque existiese un documento (carta de creencia) que lo facultase, sino por el grado de complicidad preciso. Este

${ }^{63}$ J.F. JIMÉNEZ ALCÁZAR, Un concejo de Castilla, p. 315. Acerca del suceso, véase $\mathrm{M}^{\mathrm{a}}$ Isabel DEL VAL VALDIVIESO, La Farsa de Avila en las crónicas de la época, en Espacios de poder $y$ formas sociales en la Edad Media. Estudios dedicados a Angel Barrios, Salamanca, 2007, pp. 357-367.

${ }^{64} \mathrm{R}$. SALICRÚ I LLUCH, La Corona de Aragón y los nazaritas en el segundo reinado de Muhamad el Pequeño (1427-1429), en Actas del Congreso La frontera oriental nazarí, pp. 203204. Lo recoge asimismo, y de forma más contextualizada, en El sultanat de Granada, pp. 228229 .

${ }^{65}$ M.M. MARTÍNEZ AlMiRA, ob. cit., p. 488. 
factor, ciertamente muy poco medible, encontraba su punto de referencia en la plasmación institucional que legitimaba las distintas acciones y decisiones.

El mercader o almayar fronterizo, que cruzaba en un sentido y otro la delimitación con Granada o con Aragón, será un elemento clave en el mantenimiento de este canal comunitativo. Si hay comerciantes valencianos tratando en la mismísima raya con Granada (Fuente la Higuera ${ }^{66}$, es lógico suponer que tuvieron algún papel en esas relaciones ${ }^{67}$. Tenemos el caso en 1404, donde el acercamiento entre aragoneses y nazaríes se realizó de manera informal a través de un mercader que estaba en Granada, Pere de Banya, pero que permanecía en contacto con el Baile General del Reino de Valencia, Nicolau Pujades, y con el jurista valenciano Joan Mercader ${ }^{68}$.

Judíos o no, mercaderes, regidores o justicias, nobles, prohombres, hidalgos o abonados, la condición de mensajeros sostuvo la urdimbre de las relaciones existentes en todo el territorio como elementos claves para el contacto diplomático de bajo nivel. El siguiente paso será la versatilidad de determinados oficios emanados del uso fronterizo para esa misma función.

\subsection{Oficios fronterizos al servicio del contacto diplomático}

En efecto, la costumbre condicionaba la gestación de instituciones concretas por parte de los distintos poderes que articulaban las fronteras; es más, serán los propios individuos los que gestionaron en ocasiones fórmulas de entendimiento para hacer posible y mantener abierto el canal de comunicación.

La gestión diplomática al más alto nivel no es tema de este estudio, y se desarrolló básicamente por delegaciones expresas de los monarcas en personas de reconocida posición social. Es cierto que a finales del periodo medieval, el asiento de determinados linajes sobre posiciones fronterizas de suma importancia, caso de Alcalá la Real, Tarifa o Lorca, hizo posible que la Corona delegase estas misiones de tan alta calidad (se trataba de acordar una tregua entre reyes) en individuos pertenecientes a estas familias, como Fernando de Aranda, de Alcalá, que había cogido el testigo de los señores de Aguilar y de los de Baena (condes de Cabra) ${ }^{69}$.

Pero fue la diversa población flotante que visitaba los lares fronterizos quien caracterizó perfectamente el contacto entre poderes locales. En el caso del sector oriental granadino confluían personas que desempeñaban oficios similares, pero adscritos a organigramas institucionales distintos. El encargado

\footnotetext{
${ }^{66}$ AHML. Pleito de Vera, f. 13v.

${ }^{67} \mathrm{~A}$ este respecto, véase el estudio de J.E. LÓPEZ DE COCA CASTAÑER, La frontera de Granada (siglos XIII-XV). El comercio con los infieles, en Cristianos y musulmanes en la Península Iberica: la guerra, la frontera y la convivencia, León, 2009, pp. 367-392, en concreto pp. 370 y ss.

${ }^{68}$ R. SALICRÚ I LluCh, El sultanat de Granada, p. 33.

${ }^{69}$ José RodríGuez MOlina, J. GARCÍA BALLESTER, Alcalá la Real, enclave generador de tratados de paz, "Actas de VII Estudios de Frontera", pp. 795 y ss.
} 
de rescatar cautivos, bien como alfaqueque o bien como ejea ${ }^{70}$ (sin que hasta la fecha se pueda precisar con garantías la diferencia de competencias entre ambos, si es que la hubiera), tenía su correspondiente tanto en el lado nazarí, tanto en el castellano como en el valenciano. Independientemente de si se adscribía a competencia de oficio municipal o real, lo cierto es que estos personajes trascendían el hecho del simple cargo concejil ${ }^{71}$. La clave se localiza de nuevo en la necesidad de reconocimiento de autoridad, que se lograba casi en exclusiva por el factor tiempo: la confianza se genera a través del contacto repetido.

Es cierto que el alfaqueque, en tanto que mediador ${ }^{72}$, era la persona que estaba más habituada a negociar y tratar con los núcleos de más allá de los límites fronterizos. La verdad es que eran estos individuos los que el resto de enclaves reconocían como legítimos para pactar y resolver problemas permanentes del cautiverio. El hecho de que a lo largo del siglo XV, los alfaqueques oriolanos escribiesen a su municipio desde Lorca ${ }^{/ 3}$, nos hace insistir en la estrecha relación y mantenimiento de red comunicativa entre los dos enclaves a la hora de referirse a los asuntos vinculados con Granada y los cautiverios inherentes a la existencia de la Frontera de Granada. Para una cuestión de cuatro vecinos veratenses, Pere Tomás, como alfaqueque de Orihuela, escribirá a la ciudad del Bajo Segura desde Lorca (en castellano). Barrio Barrio, en el análisis que realiza del oficio en su estudio sobre el consell oriolano de estos primeros años del $\mathrm{XV}$, alude precisamente a esa circunstancia $^{74}$. Ese proceso, y según lo especificado en la documentación ("E la carta de Bera es en morisco e venia esplanada, que diu axi..." $)^{75}$ podría funcionar la siguiente forma: una vez se recibía por el alfaqueque de Orihuela la misiva, se traducía en Lorca, con lo que la carta se abría, llegando al consell ese original con el sello roto ya ("esplanada", es decir, alisada, desplegada) junto con la traducción, que bien podía estar en valenciano o bien en castellano (en este caso anterior lo está en valenciano). En ese sentido, cabe insistir en la versatilidad de un sistema que buscaba soluciones y las encontraba, seguramente fruto del uso y la costumbre, gestada a lo largo del siglo XIV. Es el que permitía la colaboración estrecha entre alfaqueques de diferentes jurisdicciones, que en ocasiones acudían en parejas para la correcta mediación:

"A los honrados el justiçia e jurados de la villa de Orihuela, nos el conçejo e caualleros e escuderos, ofiçiales e ommes buenos de la villa de

\footnotetext{
${ }^{70}$ Véase nota 37.

${ }^{71}$ J.A. BARRIO BARRIO, Gobierno municipal en Orihuela, p. 155.

${ }^{72}$ Éstas son literalmente las palabras de Manuel GonZÁLEZ JIMÉNEZ en el Prólogo de la edición facsímil de la obra recopilatoria de J. de M. CARRIAZO, En la frontera de Granada, Granada, 2002, p. XX.

${ }^{73}$ Por ejemplo, la correspondencia remitida por el alfaqueque Pere Tomás en 1417 (AMO. Libro 16, f. 54v.).

${ }^{74}$ J.A. BARRIO BARRIO, Gobierno municipal, p. 155, nota 407.

${ }^{75}$ AMO. Libro 16, f. 39v.
} 
Lorca nos enbiamos mucho a saludar como aquellos para quien mucha honra e buena ventura querriamos. Vimos la carta que nos enbiastes sobre rason de los quatro moros que desides que y tenedes enbargados, e todo lo en ella qontenido. Saber que ante que la dicha vuestra carta aqui llegase, tres dias avia que veno aqui a esta villa Hamet Alvelleçi, moro alfaqueque de Bera, e segunt aparesçe los dichos moros son de la dicha Bera. E pidieronlos a nos, sobre lo qual van alla a vos Alfonso Garçia de Guivara, nuestro alfaqueque, e el dicho Hamet Alvelleçy, otrosi alfaqueque de la dicha Bera. Porque bivamos en pas e en sosiego sera cosa que vos agradesçeremos mucho. Que devos Dios su graçia. Fecha XIIII dias de febrero año de MCCCC XVII años. Alfonso Fernandez, escrivano"76.

Esta cuestión es importante, ya que en ocasiones se trataba de contactos directos entre los núcleos, como cuando en 1474 el multisecular asunto de unos cautiverios no aclarados, marcharon mensajeros desde Vera (Abolax) y Lorca, que intervenía con dos regidores (los aludidos Juan Ponce y Diego de Otón), pero que actuaban sencillamente como enviados ${ }^{77}$, y no como alfaqueques; es el hecho al que he hecho alusión en diferentes momentos a lo largo del presente estudio. Lo interesante es que sus cartas de creencia les concedían la plena legitimidad para negociar en nombre de su aljama y concejo, respectivamente. La existencia de un intérprete judío era altamente significativa sobre todo para el trato directo entre los oriolanos y el nazarí veratense.

La labor de los alfaqueques, en actuaciones realizadas a tres bandas, es muy interesante por lo que trascendía de sus actividades habituales como rescatadores de cautivos. El hecho de su reconocimiento se basaba en la legitimación recibida por parte del concejo, consell o aljama a la hora de solventar con todas las garantías legales (fronterizas) esos cautiverios, cuestiones que ocupaban en gran medida las relaciones habidas entre las partes (lógicamente de los dos reinos cristianos con el sultanato islámico peninsular).

Entre las condiciones personales que debía tener un alfaqueque, Torres Fontes señala algunas que encajan perfectamente en esa aura de autoridad reconocida, como el dominio de lenguas, la facilidad para el trato y "habilidad para ganar amigos"78, leamos por tanto registro no hostil por parte de la otra parte. Por lo tanto, el contacto de estos individuos, protagonistas como pocos del paisaje fronterizo con las ciudades de referencia es inherente a su propia dinámica, al punto que casi entra en la lógica el hecho de que hubiera algún caso de "lealtad" a más de un concejo, como el ejemplo de Pedro Gras, alfaqueque lorquino, a quien Alfonso XI llegó a dar orden de

\footnotetext{
${ }^{76}$ AMO. Libro 16, f. 39v.

77 “Johan Pons, vostre misatger, qui es vengut en companya de Abolaix, moro misatger de la ciutat de Bera, e Samuel Avenyayon, juheu, ab ells hoyt lo dit vostre misatger e ve axi lo dit moro per miga del dit juheu..." Misiva de Orihuela a Lorca. AMO. A-32, f. 56r. Pieza documental mencionada por M. MÄRTÍNEZ ALMIRA, ob. cit., p. 458, nota 3.

${ }^{78} \mathrm{~J}$. TORRES FONTES, La frontera, sus hombres y sus instituciones, en "Instituciones y sociedad en la frontera murciano-granadina", Murcia, 2004, p. 67. Este artículo fue publicado en "Murgetana", LVII (1980), pp. 71-116, y en Estampas medievales, Murcia, 1988, pp. 183-250.
} 
coger preso por atender al interés granadino siendo oficial cristiano ${ }^{79}$. O también el que desplegasen prácticas contrarias al recto ejercicio de su cargo, como el del espionaje ${ }^{80}$. Pero lo normal es que se respetasen las personas y bienes entre los tres enclaves. Cosa distinta fue la posición de la ciudad de Murcia con respecto a sus particulares relaciones de vecindad con Orihuela; el mencionado Pere Tomás fue objeto de agravio y saqueo por parte de los alcaldes de las sacas murcianos en 1416, a lo que tuvo que rectificar el concejo de la capital para mantener las buenas relaciones. Y nos referimos a un individuo que muy poco tiempo después tuvo que dejar su oficio por enfermedad, pero que el consell oriolano lo suplió por Daniel Tomás ${ }^{81}$ (no he podido documentar su posible filiación, pero que es lógico suponerla por cuanto asumía la autoridad heredada del antecesor en el oficio), es decir, un personaje de actividad permanente en la frontera y habitual en la demarcación.

Como mediación para evitar males mayores, surgió al amparo de esa necesidad fronteriza la institución del alcalde mayor entre moros y cristianos $^{82}$, aunque en este caso sus propias competencias y para el caso murciano no se corresponderán con esa legitimación de poderes locales, pues venía condicionado su nombramiento por los monarcas, o en el caso de los cristianos y en alguna ocasión, por algún adelantado; para la Alfaquequería Mayor era el mismo sistema de designación real, por lo que he hecho hincapié en los concejiles, lógicamente. Además de esa autoridad reconocida por la teoría del derecho consuetudinario fronterizo, es importante aludir a la práctica cotidiana, pues, en palabras de González Jiménez "su capacidad de intervención dependía de su propio prestigio, de la índole de sus relaciones con los grandes concejos de la zona y hasta de su audiencia ante la corte granadina" 83 .

Existieron otras instituciones de menor entidad aunque de importancia crucial para la resolución de los cautiverios, como los fieles del rastro, pero que no tendrán esa proyección para el acto comunicativo al que nos estamos refiriendo, aunque sí es cierto que pertenecerán al conjunto global que sostenga la red establecida entre los diversos poderes locales aludidos.

\subsection{Castellano, catalán, árabe y hebreo en una frontera multilingüe: misivas, traductores e intérpretes}

La realidad de ese canal de comunicación y entendimiento sólo fue posible por la existencia de una línea sostenida de misivas, traductores,

\footnotetext{
${ }^{79}$ J. TORRES FONTES, La frontera, sus hombres, p. 64.

${ }^{80} \mathrm{~A}$ finales del XIV, el consell de Orihuela expulsó al alfaqueque de la villa murciana de Molina bajo esta acusación. Ibídem, p. 63.

${ }^{81}$ J.A. BARRIO BARRIO, Gobierno municipal, p. 154.

${ }^{82}$ Véase nota 38. Es muy interesante el procedimiento de vistas planteado por Juan ABELLÁN PÉREZ para el sector xericense (Vistas entre moros y cristianos, en "Actas de VII Estudios de Frontera", pp. 25-36).

${ }^{83}$ Manuel GonZÁLEZ JiMÉNEZ, Prólogo, p. XV.
} 
intérpretes y uso de las diversas lenguas de forma nada traumática ni problemática en los diversos ámbitos documentados. Y eso que se planteó una situación ciertamente compleja en un territorio no muy grande como lo es el Sureste de la Península ${ }^{84}$. Porque también hay que dejar clara una cuestión: una cosa era la comunicación entre Lorca y Orihuela, tal y como he aludido en el capítulo correspondiente, y otra bien distinta entre cualquiera de las dos anteriores con la musulmana Vera. La precisión de un traductor (el escribano de lo morisco ${ }^{85}$ documentado en la ciudad del Guadalentín) con el fin de entender las misivas nazaríes era evidente ${ }^{86}$. Pero hablamos no de un oficial real, como lo habrá posteriormente en el XVI, o al servicio de la Real Chancillería para los pleitos abiertos que así lo precisaron (como Juan Rodríguez o el propio Alonso del Castillo) ${ }^{87}$, sino de individuos concretos que tenían esos conocimientos idiomáticos. Insistimos en que el problema no se generaba entre murcianos y oriolanos, ya que ese sistema de bilingüismo pasivo generado también por el contacto tan directo, hacía posible que se mantuviera el canal de comunicación. No obstante, sí hubo problemas puntuales que necesitaban una precisión para no desvirtuar o malinterpretar el mensaje, como el acuerdo mencionado del concejo murciano en 1416 acerca de la necesidad de un traductor del catalán ${ }^{88}$; reitero que dudo mucho que este conflicto existiese tal y como quedaba planteado, pues la literalidad del fragmento permite exponer que se trataba de una precisión para evitar problemas futuros, no que fuese ininteligible. De hecho, las cartas entre Lorca y Orihuela fueron habituales, los unos escribiendo en castellano y los otros en catalán, sin que hubiera mayores problemas. La solución nos la ofrece los grandes vaivenes demográficos de ese siglo XV, pues se puede documentar que el porcentaje de murcianos (de la capital y de Lorca) establecidos en la ciudad orcelitana durante esos años fue altísimo ${ }^{89}$; escasos conflictos habría por lo tanto. Tenemos el caso de que, en ocasiones, el propio adelantado mayor del reino de Murcia se dirigirá a los oriolanos en catalán ${ }^{90}$.

Por lo tanto, observamos la cuestión de las cartas en árabe como principal escollo del canal comunitativo. La solución más cotidiana será la de recurrir al uso de algunos individuos judíos, normalmente dedicados al mercadeo como almayares con los nazaríes, que habitaban en todo el sector

${ }^{84}$ J.F. JiMÉNEZ AlCÁZAR y Ma ${ }^{\mathrm{a}}$.M. ABAD MERINO, Fronteras lingüísticas.

${ }^{85}$ Véase nota 56.

${ }^{86}$ Acerca de la importancia de la lengua en los contactos entre genoveses y granadinos, véase el estudio de Antonio PELÁEZ ROVIRA: Reflexiones sobre la evolución de la frontera socioeconómica entre Génova y el emirato nazarí de Granada, en "Actas de VII Estudios de Frontera...", pp. 656-657.

${ }^{87} \mathrm{M}^{\mathrm{a}}$ Mercedes ABAD MERINO, La traducción de cartas árabes en un pleito granadino del siglo XVI. El fenómeno del romanceado como acto judicial: Juan Rodríguez y Alonso del Castillo ante un mismo documento, "Al-Qantara", 2010, en prensa.

${ }^{88}$ Véase nota 58.

${ }^{89}$ Juan Antonio BARRIO BARRIO, La inmigración en Orihuela entre 1421 y 1428 , en La población valenciana. Pasado, presente y futuro. Actas II Jornadas de estudios sobre la población valenciana, Orihuela 1996, vol. I, Alicante, 1998, pp. 171-186.

${ }^{90}$ AMO. Libro 16, f. 53r. 
murciano. Tenemos un ejemplo excelente en el caso de 1474-75, donde la carta en árabe conservada en el archivo oriolano es seguro que fue traducida por Samuel Abenhayón ("per miga del dit juheu [Samuel Abenyayón]") Aquí es momento de aludir a estos judíos como mediadores interculturales ${ }^{92}$, pues su actividad comercial les facilitaba el tránsito de unas demarcaciones a otras; y como el desarrollo de esa misma labor necesitaba de un conocimiento fluido de lenguas, este rasgo los convirtió en los personajes inherentes a esa labor traductológica e interpretativa. Pero ni todos los judíos sabrían árabe ni todos eran expertos negociadores. El asiento de juderías en el Sureste lo podemos documentar desde el mismo momento de la conquista castellana, y en concreto, tanto en el caso de Orihuela como en Lorca y Murcia, fueron vecinos habituales, con las correspondientes fluctuaciones fruto de las coyunturas socio-políticas de esos siglos. La aljama lorquina, asentada en el $\mathrm{XV}$ en el solar de la fortaleza, estará compuesta por unas pocas decenas de individuos que ha terminado dejando mayores restos materiales que documentales. Este estado de semi-ocultación en los documentos conservados se debe a muchos motivos, aunque el principal puede ser el de ser una zona fronteriza con grandes alteraciones en su población, que hallaba su asiento en las distintas comunidades judías de la zona, bien en la demarcación murciana, como en la oriolana o la granadina ${ }^{93}$. La carta remitida por el concejo de Lorca al de Orihuela, donde se especifica la delegación de los mencionados dos regidores, Juan Ponce y Diego de Otón, acompañando al mensajero veratense Abolax, es uno de los mejores ejemplos de los que podríamos disponer para ver gráficamente a lo que me refiero. Entre líneas, y medio borrado, el escribano añadió que acompañaba a la comitiva Samuel Abenyayón, judío ${ }^{94}$. La corroboración de su presencia y de los motivos de la misma (servir de intérprete al granadino) la tenemos documentada en la correspondencia a la que va a dar lugar la llegada de los tres jinetes a la ciudad oriolana. Ya hemos visto a otro judío realizar labores de traducción escrita (Çafad Díaz). Quede la cuestión como un factor más en la compleja situación lingüística del Sureste peninsular bajomedieval.

La realidad de la lengua utilizada en las idas y venidas de las distintas cartas entre las instituciones concejiles mencionadas no guarda una estructura fija. Lo habitual es que el consell de Orihuela se dirigiese a las distintas autoridades castellanas en catalán, comenzando por la vecina Murcia y terminando por la más lejana Lorca; pero también a Vera, por lo que queda la hipótesis abierta de si se traducían en territorio granadino o pasaban previamente por el catalizador (más que filtro) lorquino. Lorca y Murcia

\footnotetext{
${ }^{91}$ AMO. Libro A-32, f. 56r.

${ }^{92}$ SALICRÚ I LluCH, R.: Más allá de la mediación de la palabra: negociación con los infieles y mediación cultural en la Baja Edad Media, en Negociar en la Edad Media, Barcelona, 2005, pp. 409-439.

${ }^{93}$ Se documentan judíos en Purchena y en la propia Vera. ARCG. 454-1. Orihuela.

${ }^{94} \mathrm{AMO}$, Documentos sueltos. A-32. 1474, agosto, 23. El concejo de Lorca al consell de
} 
siempre escribieron en castellano, y posiblemente tanto en el caso oriolano como en el regional murciano se trate de una cuestión de implicaciones sociolingüísticas fruto de cómo se terminó de configurar el reino y la Procuración General de Orihuela después de Torrellas, hecho que nada tendrá que ver ni con la verdadera comprensión de los mensajes ni con otra cuestión cultural, pero que sí lo fue con la correspondencia nazarí. En este sentido, es importante conocer el papel jugado por el adelantado mayor del reino de Murcia como poder territorial tanto en su perspectiva hacia el interior como hacia el exterior (reconocimiento de la autoridad en el seno de la demarcación propia por parte de Orihuela; insistiré en el apartado siguiente sobre este asunto).

\section{CONCLUSIONES: \\ LA LEGITIMACIÓN DEL PODER LOCAL COMO INTERLOCUTOR VÁLIDO ENTRE REINOS}

La realidad de una frontera tremendamente activa en todos los planos, desde el militar ofensivo hasta el de negociación obligada o necesaria, va a repercutir de manera directa en la forma de asumir esa misma situación. Y la apropiación (o encarnación más bien) de sus papeles la plantearán los intervinientes sin apenas dudarlo en ningún momento, tanto si se trató de entes institucionales (poder local, poder territorial o poder central) como si lo fue a título individual por los personajes que poblaron y dieron vida a esas demarcaciones limítrofes. Por un lado, se ha expuesto la importancia del nivel más directo en las relaciones interterritoriales, como lo fueron los contactos personales entre los individuos que definieron esos actos comunicativos, tanto intérpretes como alfaqueques como almayares, todos actuando en muchas ocasiones como mensajeros o sencillamente asumiendo competencias diversas en aras de conseguir objetivos precisos.

Fueron estos puntos de contacto los que terminaron por delimitar las líneas de legitimación política, pues el reconocimiento particular de la autoridad encarnada por alguna de esas personas condicionaba comportamientos de unos y otros. Ni se enviaba a cualquier mensajero, ni se recurría a la improvisación a la hora de remitir una representación: el personaje marchaba no sólo con una carta de creencia, imprescindible por cuanto suponía la autorización (y legitimación) para su labor, sino que se solía pertrechar de acompañantes que le facilitasen el mantenimiento de los canales de comunicación abiertos, bien por razones lingüísticas bien por motivos de reconocimiento y confianza previa.

La necesidad de resolver situaciones trágicas en el ámbito más particular de los cautivos, situaciones que suponían la mayor parte de los asuntos interfronterizos entre los tres Estados, o lo que era lo mismo y lo que es el mayor interés para el objetivo propuesto en este estudio, entre los tres núcleos, convertían a esas mismas relaciones en cuestiones de representación de poderes centrales. Lorca era Castilla, Vera era Granada y Orihuela era Valencia. Y en consecuencia se actuaba: el concejo lorquino asumía la 
voluntad del rey castellano, la aljama veratense la del sultán nazarí y el consell oriolano la del monarca aragonés. Los negociadores que se desplazaban por el Corredor del Mediterráneo en este tramo del Sureste peninsular tenían meridiano conocimiento de que sus acciones repercutían no sólo en la represalia sino que llegaban a implicar al entorno más inmediato de los monarcas, sobre todo en el caso del morador de la Alhambra. En este sentido, contamos con el especial interés que el municipio oriolano puso en la cuestión abierta por el cautiverio de unos vecinos ${ }^{95}$, y que puso especial empeñó en que el sultán tuviese conocimiento de lo sucedido; año 1417.

Lo más interesante de toda esta interrelación entre enclaves que asumían estas autoridades de poder más elevado del que a priori se les presuponía, es el reconocimiento del resto de núcleos circundantes y de los otros dos a su vez. La conclusión más evidente y más importante es que encarnaban propiamente la articulación de organización espacial de todo el territorio, a pesar de que ser cruzado por dos fronteras políticas tajantes. La referencia de Castilla para los nazaríes de Vera no era Murcia, sino Lorca; y la del reino de Valencia, tampoco era la capital del Júcar, sino Orihuela; si acaso es de sumo interés el hecho de que los veratenses recurriesen al intermediario castellano buscando una estabilidad fronteriza que a todos interesaba. En alguna ocasión he utilizado un aserto del profesor Hinojosa Montalvo acerca de la vinculación de las posturas murcianas más favorables hacia los granadinos que hacia los valencianos, protestas que se elevaron desde las autoridades valencianas argumentando que se trataba de algo ilógico tratándose ambas de ciudades cristianas y Vera musulmana ${ }^{96}$. El asunto cabe explicarlo en la situación de vanguardia fronteriza castellana, donde era Lorca la primera en recibir la represalia en el caso de una reacción nazarí. No obstante, también habría que poner sobre la mesa las razones de tipo particular; el hecho de asumir el concejo de Lorca la custodia del mensajero musulmán para resolver el problema entre granadinos y oriolanos, no tiene por qué representar mayor trascendencia que la de una responsabilidad adquirida y desempeñada en el contexto fronterizo, tal y como he ido aludiendo a lo largo del estudio. Incidiendo en lo dicho, es igualmente significativo que fuese Orihuela la referencia para todas las cuestiones que los veratenses tuvieron con valencianos, mallorquines o ibicencos. Y lo más importante era que el consell oriolano así lo asumía. El poder central del monarca aragonés encontraba un recurso de autoridad en uno de los extremos más lejanos a sus puntos neurálgicos de su esencia política. Pero también lo fue como referente de potestad, y he aquí la magnitud y trascendencia de la

\footnotetext{
${ }^{95}$ Contestación del rey granadino. AMO. Libro 16 , f. $68 \mathrm{v}$.

${ }^{96} \mathrm{~J}$. HINOJOSA MONTALVO, Las relaciones del municipio valenciano con Murcia y Lorca durante los siglos XIV y XV, en Homenatge al doctor Sebastiá García Martínez, Valencia, 1988, p. 140 .
} 
acción política de los distintos núcleos locales ${ }^{97}$. La intervención del mensajero (regidor, jurado, caudillo, alfaqueque) y de su recurso comunicativo (control de la lengua, bien directamente bien a través de un intérprete), se reflejaba en el nivel del poder local. Pero el apartamiento geográfico y la necesidad de una resolución rápida de asuntos urgentes, hacía que esos núcleos asumieran esas competencias propias de poderes no sólo territoriales sino centrales. Sólo un caso distorsionaba la red, la figura territorial del adelantado mayor del reino de Murcia, reconocida sobre todo por las autoridades de Orihuela a la hora de dirigirse a la demarcación murciana. Y no iban desencaminados, pues la propia definición de la institución marcaba esa referencia. La competencia en asuntos jurisdiccionales en todo el territorio del reino lo hacía responsable último de cualquier decisión vinculante que obligaba al resto de núcleos, desde la propia capital, a las posiciones de vanguardia fronteriza en la realenga Lorca o en la santiaguista Caravaca, hasta las cuestiones corsarias en la costa, más cuando el puerto de Cartagena esté bajo el señorío de los propios adelantados (caso de don Juan Manuel en la primera mitad del XIV o en la segunda de la centuria siguiente, formando parte de los patrimonios de don Pedro Fajardo y Quesada y de su yerno don Juan Chacón).

No se puede vincular en el periodo medieval de un modo tajante la utilización política de la lengua a la hora de definir relaciones encontradas. Es evidente que una situación de bilingüismo pasivo mantuvo abierto el canal de comunicación entre Lorca y Orihuela por asuntos fronterizos, más difíciles en el caso de la ciudad de Murcia por razones de vecindad bien entendida unas veces, y otras mal. La cotidiana presencia de individuos a un lado y otro de las permeables fronteras murciano-oriolanas hace posible pensar en un panorama de coexistencia de lenguas establecidas cada una en sus demarcaciones y sin mezcla como señales de identidad. El judío morador en todos y cada uno de los núcleos principales de la frontera, en todas las demarcaciones, se convirtió en un personaje activo por su papel de relación permanente entre las propias comunidades y como puente para castellanos, aragoneses y granadinos. Los años finales del XV fueron de profundos cambios. No obstante, la desaparición del poder musulmán nazarí no sólo no varió el sistema de red organizativa del territorio, sino que la profundizó, aunque con distintos elementos. En el caso de Vera, al ser repoblada casi enteramente con familias murcianas (lorquinas), y situarse en un paraje tan lejano al control directo de la Capitanía General regida por el conde de Tendilla, casi era obligada la relación muy estrecha con la ciudad que le era referente para su refundación (incluso después del terremoto de 1518). Ya aludí al apoyo de las milicias

\footnotetext{
${ }^{97}$ Acerca de las relaciones entre centro y periferia en el contexto de la existencia de una frontera, y como punto digno de ser observado, véase André BAZZANA, El concepto de frontera en el Mediterráneo Occidental en la Edad Media, en Actas del Congreso La frontera oriental nazarí, p. 31. Y de forma global sobre la concreción de estos espacios fronterizos con referencia al cada vez más poderoso poder central del Estado Moderno, es interesante la obra de Benedict ANDERSON, Reflexiones sobre el origen y la propagación del nacionalismo, México, 1991.
} 
lorquinas para la defensa marítima veratense en la segunda década del XVI, por no mencionar los sucesos de 1569 (también expuestos).

La cuestión particular del obispado de Orihuela a partir de los primeros años del XVI hizo variar ese paisaje, pues se llegó a un enfrentamiento directo entre las posiciones murcianas (alentadas claramente por el primer marqués de los Vélez) y las oriolanas: las Germanías fueron la excusa que llevó a la catarsis colectiva. Si las máquinas de guerra utilizadas en el asedio de la Guerra de los Dos Pedros estuvieron expuestas a la entrada de la ciudad de Murcia, serán las banderas del saqueo de 1521 las que decoren la capilla de los Fajardo en la catedral. La lengua pasaba a ser un elemento más de identificación, hecho que se va a diluir conforme avance el XVI y definitivamente en el XVII cuando Orihuela marche hacia el uso del castellano como lengua vehicular antes incluso de la aplicación de los decretos de Nueva Planta $^{98}$.

No obstante y para entonces, los papeles jugados por los tres referentes territoriales van a quedar como puntos de articulación supracomarcal, más que nada por el calibre del poblamiento. Ni en Vera el entorno le ofrecía mayor competencia, ni a Lorca y Orihuela, al margen de la fagocitación ejercida por la ciudad de Murcia (a la que ni Lorca ni tan siquiera Vera escaparon), les amenazó esa situación. La ciudad alicantina tuvo la oportunidad para desempeñar su papel referencial respecto a los numerosos enclaves de la Vega Baja del Segura por la residencia del obispo. Fue el caso frustrado de Lorca, cuando en el XVIII también intentó erigir una sede obispal retrotrayendo la existencia de un obispo en el concilio de Elvira de 319.

Pero la situación en el periodo moderno fue sustancialmente distinta, ya que lo que se había configurado en las primeras décadas del XIV, después de Torrellas, había sido un sistema apuntalado por la lejanía de estos territorios a los distintos núcleos de los poderes centrales, situados además en una frontera múltiple, con lo que hay de inaprehensible respecto del control directo que comportaba esa localización. El ejercicio de la potestad se realizaba a través de ese contrato político que suponía la encarnación del monarca en las defensas (fortalezas fundamentalmente como elemento de autoridad y realidad militar) de las distintas ciudades fronterizas. Fueron contactos directos interregionales bendecidos por los poderes centrales, traspasados a los territoriales, que fueron los que terminaron por definir la cuestión, y en ocasiones por los locales, que fueron los que lo concretaron y ejercieron. Es la legitimación del poder soberano procedente de la asunción de lo que representa el poder real en sus concejos. El rey de Castilla no intervendrá salvo excepciones en la dinámica diplomática de bajo nivel desarrollada de manera cotidiana (si entendemos como tal la normalidad de una situación dada). Las cuestiones jurisdiccionales del reino ya las había delegado el monarca al momento de asentar un adelantado mayor en la demarcación recién conquistada; y las de mantenimiento de la frontera en su

${ }^{98} \mathrm{M}^{\mathrm{a}} \mathrm{M}$. ABAD MERINO, El cambio de lengua en Orihuela. Estudio sociolingüístico-histórico del siglo XVII, Murcia, 1994. 
concejo de Lorca. Hablamos de un umbral de actividad permanente nunca dormida, y esa perenne sensación de dinamismo (debido sobre todo al fenómeno del cautiverio) es la que convertirá a núcleos como Lorca, al igual que Jerez, Alcalá o Écija en torres básicas del gran juego de ajedrez fronterizo que supuso todo este complejo contexto. La concesión de las villas almerienses de Huércal y Overa en agosto de 1488 al municipio lorquino tenía esa premisa. Lo importante es que personas e instituciones asumieran esta catalogación de papeles tan definidos.

Fecha de recepción del artículo: mayo 2010.

Fecha de aceptación y versión final: julio 2010. 


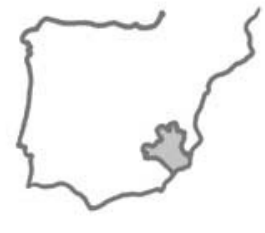

Reino de Murcia

-Corona de Castilla-

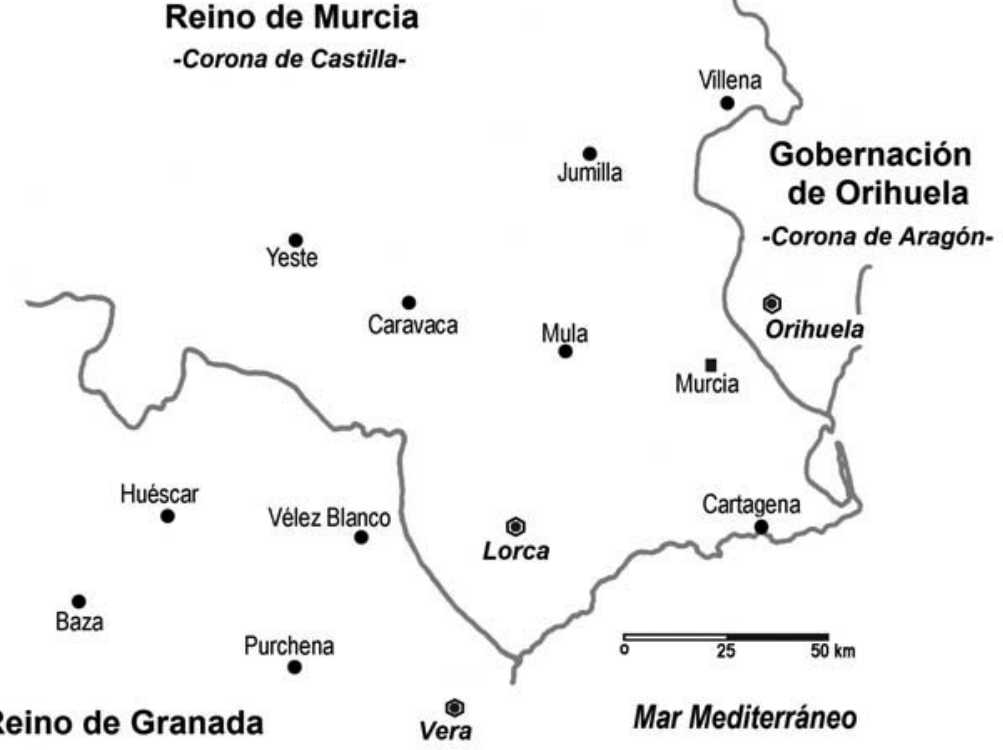

